\title{
University Choice: The Role of Expected Earnings, Nonpecuniary Outcomes, and Financial Constraints
}

\section{Adeline Delavande}

University of Technology Sydney and Nova School of Business and Economics

\section{Basit Zafar}

Arizona State University and National Bureau of Economic Research

\begin{abstract}
We investigate the determinants of students' university choice in Pakistan, with a focus on monetary returns, nonpecuniary factors enjoyed at school, and financial constraints. To mitigate the identification problem concerning the separation of preferences, expectations, and market constraints, we use rich data on subjective expectations, with direct measures of financial constraints, to estimate a life-cycle model of school choice jointly with school-specific expectations of dropping out. We find that labor market prospects play a small role. Instead, nonpecuniary outcomes, such as the school's ideology, are the major determinants. Policy simulations suggest that relaxing financial constraints would have large welfare gains.
\end{abstract}

\section{Introduction}

Higher education participation has expanded considerably worldwide in the last 50 years, moving in the direction of a mass system of education.

We would like to thank Maricar Mabutas, Victoria Gregory, Ellen Fu, and, in particular, John Conlon for outstanding research assistance. We thank James Heckman (the editor) and four anonymous referees for comments and suggestions. This paper has also benefited from comments from Peter Arcidiacono, Sonia Bhalotra, Zach Bleemer, Lance Lochner, Steve Pudney, Chris Taber, Joao Santos Silva, Todd Stinebrickner, Luis Vasconcelos, 
Simultaneously, higher education systems are undergoing changes, such as the growth of for-profit universities in the United States, the emergence of a vibrant private sector in many developing countries, and the creation of universities by religious organizations in Latin America and Asia (Task Force on Higher Education and Society 2000). High school graduates, therefore, have a very wide range of options of higher education institutions available to them, which differ in terms of quality, cost, and other important characteristics. In this paper, we estimate a life-cycle utility model of university choice to investigate the determinants of the choice of higher educational institutions.

We focus on the role of expected monetary returns, nonpecuniary factors enjoyed at school, and financial constraints in university choice, conditional on participation in higher education. Understanding the relative role of preferences, expectations (or information sets), and market structures is challenging with the type of data on school attendance and family background typically available (e.g., Cunha, Heckman, and Navarro 2005). The reason for this challenge is a threefold identification issue. First, expectations about future earnings are usually not observed. Second, students' expectations about nonpecuniary outcomes enjoyed while at school are similarly usually not observed. Making inference on the decisionmaking process based on choice data and maintained assumptions on expectations is problematic since observed choices might be consistent with several combinations of expectations and preferences (e.g., Savage 1954; Manski 1993). Finally, data typically available do not provide a direct way of identifying which students are credit constrained (e.g., Lochner and Monge-Naranjo 2012).

In this paper, to circumvent these identification issues, we use new data on (i) subjective expectations about labor market outcomes, (ii) subjective expectations about nonpecuniary factors (namely, alignment of the school's teachings with one's own ideology, parental approval, and graduation rank), (iii) subjective expectations of dropping out, (iv) choice sets reflecting which schools are in each student's budget constraint, and (v) stated school choice with and without financial constraints. We estimate a life-cycle utility model of university choice without having to make strong assumptions on expectations about labor market outcomes and nonpecuniary factors, or about which students are financially constrained. By combining data on stated choices and expectations held at the time of the choices, we can separate expectations from preferences.

\footnotetext{
Matthew Wiswall, and participants at various conferences and seminars. We are enormously indebted to our local field teams and participating institutions, for without their assistance this project would not have reached its conclusion. Funding for data collection through a RAND independent research and development grant is gratefully acknowledged. Delavande acknowledges funding from the Economic and Social Research Council Research Centre on Micro-Social Change (grant ES/L009153/1). Data are provided as supplementary material online.
} 
For this purpose, we survey male students of college-going age who are currently pursuing the equivalent of a bachelor's degree in different types of colleges in two urban centers in Pakistan. Students are provided with a hypothetical scenario of school choice, and asked to rank five different existing universities in terms of their preference of enrolling in them (assuming guaranteed admissions), conditional on their current financial status as well as conditional on no school costs. The former is the student's constrained stated choice, and the latter the unconstrained stated choice. This approach of using stated choice allows us to isolate students' "pure" preferences - at the time of the survey - free from other confounds, including admission, learning, financial constraints, and the role of other agents in students' past school choices. The five universities provided in the choice scenario cover the higher education spectrum in Pakistan, ranging from expensive Western-style elite (private) universities with high associated labor market returns at one end to free religious institutions (madrassas) at the other, with public universities somewhere in the middle. The Pakistani higher education system that we consider is diverse, making it useful to analyze school choice. Our setting is relevant beyond Pakistan because of the similarity of Pakistan's education system to the rest of South Asia, home to nearly a quarter of the world's population.

Our survey also collected data from students on their beliefs about various outcomes (such as graduation rank, parents' approval, and labor market outcomes) if they were to enroll in each of those five schools. We find considerable variation in students' beliefs for the outcomes considered across the different schools, as well as significant heterogeneity in beliefs across individuals within each school. The subjective belief data, however, paint a sensible picture. For example, students from all schools believe on average that age 30 earnings conditional on working and graduating from a Western-style university are substantially higher than those conditional on graduating from a madrassa, which is consistent with patterns in actual earnings data. The data also suggest that students tend to sort into institutions along the nonpecuniary outcomes; for example, beliefs regarding parents' approval and graduation rank are, on average, highest for the school the students are currently enrolled in. Likewise, average beliefs for dropout tend to be the lowest for the student's current school.

We use the stated constrained choice-that is, the stated choice under the respondent's current financial situation - and the expectations data to estimate the preference parameters for (log) consumption and for the nonpecuniary factors. Importantly, we model how the expectation of dropout depends on the same structural parameters as the ones relevant to university choice, and use both the stated choice and the subjective probability of dropout as outcomes to identify and estimate the model using a generalized method of moments (GMM) procedure.

The estimates of the structural parameters indicate that while expected earnings are a statistically significant determinant of the type of university 
chosen, they play a rather small role in the choice: the elasticity of school choice with regard to earnings is about 0.12 , comparable to similarly low schooling choice elasticities found in developed countries (Arcidiacono 2004; Beffy, Fougere, and Maurel 2012; Wiswall and Zafar 2015). On the other hand, nonpecuniary school-specific factors play a major role in the choice: we find that both parents' approval of the choice and the alignment of the school's teachings with one's own ideology are very important drivers of the choice. For example, students are willing to give up about a quarter of age 30 consumption to improve the likelihood of these outcomes by 2 percentage points.

We take advantage of the richness of the data to assess the validity of our structural model. We use the choice model preference parameters (estimated using students' constrained stated choice) to predict students' choices if school costs were set to zero. We then compare those predictions to students' stated unconstrained choices that, as mentioned above, were also elicited in the same survey. This is similar in spirit to assessing the robustness of a structural model using out-of-sample validation (e.g., Todd and Wolpin 2006; Galiani, Murphy, and Pantano 2015). The distribution of enrollment generated by the model matches the stated choice distribution under no school costs very well. This strengthens the credibility of the data quality and the modeling assumptions, and gives us greater confidence in using the model to simulate alternative policies.

Next we use our estimated parameters to simulate the impact of several sets of policies on students' welfare and enrollment. The existing literature provides empirical evidence that expectations are history and context dependent. ${ }^{1}$ So when conducting policy simulations, we allow the expectations about dropout and about parental approval that we have explicitly modeled to vary with the policy considered. We only age-adjust the other expectations as we argue that they are unlikely to be affected by the policies in the short run. We find that relaxing financial constraints by providing students with either loans or free schooling (financed by a tax on earnings during students' later working lives) would increase students' welfare substantially. Sixty percent of the students in our sample would be better off and almost 20 percent would enroll in a different school if loans to finance school costs were available. Our conclusions are largely unchanged if we take admission constraints into account. This suggests that financial

${ }^{1}$ For example, individuals who experienced a recession when young believe that success in life depends more on luck than effort (Giuliano and Spilimbergo 2014); lifetime personal experiences affect inflation expectations (Malmendier and Nagel 2016); those in sub-Saharan Africa who live in regions prone to frequent drought report larger subjective probabilities of experiencing food shortages or of having to rely on family members for financial assistance (Delavande and Kohler 2009); and those affected by recent conflict report lower expectations for their future economic situation (Bozzoli, Tilman, and Muhumuza 2011). 
constraints play a significant role in the intensive margin of university choice in a setting like Pakistan, where well-functioning credit markets are lacking and borrowing or lending is not possible for schooling. Underscoring the important role of nonpecuniary factors and the heterogeneity in tastes for school-specific ideology, we find that any policy that would make schools more homogeneous in terms of their teachings would have limited impact on enrollment but would result in welfare losses for a third of the students.

Our methodology of using strategically designed survey questions is clearly appealing since we do not have to worry about other confounds. The validity of this approach hinges on two implicit assumptions. The first is that students report their expectations (as at the time of the survey) truthfully. This is an assumption that is implicitly made when using any survey data and is not specific to expectations data. Note that our approach does not require that expectations be accurate or predictive of actual realizations (though systematic biases in expectations may have certain implications for policy). The second assumption is that the stated choices reported in the hypothetical scenarios are reflective of what respondents would do in actual scenarios. There is growing evidence that the two approaches of using stated choices or actual choices yield similar preference estimates. Mas and Pallais (2017) find that the stated approach yields preference estimates for alternative work arrangements that are similar to those from revealed choices, and Wiswall and Zafar (2018) find that preferences for workplace amenities recovered from stated hypothetical choices are predictive of actual subsequent real-world choices. ${ }^{2}$ Therefore, it seems that the stated approach yields meaningful responses when the hypothetical scenarios presented to respondents are realistic and relevant for them, as is the case for the school choice scenarios that we consider.

Our paper relates to various strands of the literature on educational choice. It belongs to a long tradition of work seeking to determine whether expectations about future earnings (or about returns to schooling) influence college attendance, college major, or occupation choice (e.g., Willis and Rosen 1979; Berger 1988; Flyer 1997; Arcidiacono 2004; Buchinsky and Leslie 2010; Beffy et al. 2012). The prior literature has relied on various

${ }^{2}$ Using stated choice, rather than actual choice, is becoming common in many fields and is similar to "conjoint analysis" and "contingent valuation" methods, used in marketing, environmental and natural resource economics, and health (Louviere, Hensher, and Swait 2000). Earlier papers in this literature found that the two approaches produce comparable utility parameters (e.g., Ben-Akiva and Morikawa 1990; Hensher and Bradley 1993; Adamowicz, Louviere, and Williams 1994). In addition, stated choices/intentions have been shown to relate strongly to actual behavior (see, e.g., Steel and Ovalle [1984] for job turnover, Delavande and Manski [2010] for voting, and Parker and Souleles [forthcoming] for consumption response to tax rebates and stimulus payments). Using strategically designed survey questions in conjunction with structural models has also been fruitfully applied to household financial decisions (Ameriks et al. 2015). 
types of assumptions (such as myopic or rational expectations) for the mapping between realized earnings and expected earnings. However, existing research from both developed and developing countries has found that individuals tend to be misinformed about the returns to schooling (e.g., Betts 1996; Jensen 2010; Wiswall and Zafar 2015).

This has prompted some empirical work on educational choice using expectations data about future earnings. ${ }^{3}$ While some work in psychology suggests that people are more likely to think in terms of frequency rather than probabilities (e.g., Gigerenzer 1991), subjective probabilities and expectations have increasingly been asked in surveys in the last 20 years. The existing evidence suggests that these elicited expectations are meaningful in both developed and developing countries, even in very low literacy settings; for example, expectations have been shown to vary with observable characteristics in the same way as actual outcomes, and expected outcomes have been found to be strongly associated with future outcomes at the individual level (see Manski [2004] and Delavande [2014] for a review in developed and developing countries, respectively).

More recently, these data have been shown to be useful to make inferences about decision-making in various domains (e.g., Lochner 2007; Delavande 2008; Stinebrickner and Stinebrickner 2014b; Wiswall and Zafar 2015). In existing work, elicited expectations are typically either (i) taken as given and combined with choice data to make inference on preferences parameters or (ii) used as the dependent variable (as an expected choice instead of an actual choice). We contribute to the expectations literature by combining both approaches: we explain a (stated) school choice that depends on various expectations, including one that is about an event the student has control over (dropout), which is in turn explicitly modeled as a function of the preference parameters influencing school choice.

Related to our work, Arcidiacono, Hotz, and Kang (2012) and Wiswall and Zafar (2015) use earnings expectations to estimate a life-cycle model, focusing on major choice in the United States. Attanasio and Kaufmann (2014) examine the role of expectations about returns to schooling and of perceptions of labor market risks in the decision to continue further education (that is, the extensive margin) in Mexico. We complement these papers by (1) directly taking into consideration nonpecuniary outcomes (such as ideology) and additional sources of uncertainty (e.g., regarding dropping out and employment), which are then embedded in a structural

\footnotetext{
${ }^{3}$ See, e.g., Giustinelli (2016) and Zafar (2011b). A related line of research, surveyed in Cunha and Heckman (2007), has been to use panel data on earnings combined with college choice information, and a framework in which one can identify (i) components of the life-cycle earnings that are forecastable and acted on at the time of the schooling decision is made, and (ii) components that are not forecastable. The papers reviewed in Cunha and Heckman (2007) estimate that for a variety of market structures and preferences, over 50 percent of the ex post variance in returns to college is forecastable.
} 
model; (2) looking specifically at the role of financial constraints; (3) using both choices and expectations as outcomes to identify structural preference parameters and allowing expectations to be policy variant; (4) conducting an out-of-sample validation of our structural model; and (5) providing the first evidence for understanding university choice on the intensive margin in a developing-country setting.

Our paper also relates to a large literature investigating the role of credit constraints in higher education (see Lochner and Monge-Naranjo [2012] for a review). As mentioned above, this is a challenging task given that most standard data sources do not provide a direct way of identifying which students are credit constrained. The literature has adopted various approaches to deal with this difficulty. ${ }^{4}$ Similar in spirit to Stinebrickner and Stinebrickner (2008), our study design bypasses this identification issue by asking students directly which schools are in their budget constraints. This allows us to identify precisely which students are financially constrained in their school choice. Furthermore, our structural model also enables us to provide evidence on the importance of credit constraints by simulating various policies that would relax those constraints. Other studies in developing countries suggest similarly that credit constraints are substantial in places like Mexico, Chile, and South Africa (Gurgand, Lorenceau, and Mélonio 2011; Kaufmann 2014; Solis 2017).

Finally, our paper also builds on a line of research on the role of nonpecuniary outcomes or psychic costs on educational choice (e.g., Cunha et al. 2005; Jacob and Lefgren 2007; D'Haultfoeuille and Maurel 2013; Stinebrickner and Stinebrickner 2014a; Abbott et al. 2016; Navarro and Zhou 2016; Jacob, McCall, and Stange 2018; Wiswall and Zafar 2018). The literature finds low educational choice elasticities with respect to earnings (e.g., Beffy et al. 2012; Wiswall and Zafar 2015), suggesting that nonpecuniary factors are important. In fact, Eisenhauer, Heckman, and Mosso (2015) argue that psychic costs play a dominant role in explaining schooling decisions, which constitutes a challenge for the economics of education. Our approach incorporates certain nonpecuniary factors directly into the choice model (for example, religious ideology, which is particularly relevant in the South Asian context) and is able to quantify their importance in driving educational choices. ${ }^{5}$ We find that these

\footnotetext{
${ }^{4}$ One approach focuses on looking at the role of income (or wealth) on college attendance (and college quality), after controlling for the student's ability and other family background (e.g., Cameron and Heckman 1998; Carneiro and Heckman 2002; Belley and Lochner 2007; Lovenheim 2011). Another approach uses differential returns to schooling for constrained and unconstrained students (e.g., Lang 1993; Card 1999; Cameron and Taber 2004). A third approach estimates structural life-cycle schooling models and evaluates various policies, including relaxing borrowing constraints (e.g., Keane and Wolpin 2001; Cameron and Taber 2004).

5 Zafar (2013), using a similar methodology, finds that enjoying studying the coursework and gaining approval of parents is instrumental in the choice of majors in the US context.
} 
nonmonetary factors play a dominant role in school choice in a developing setting. Given that prior literature has been unable to get into the black box of psychic factors, the approach used in this paper illustrates the potential of using such methods to understand the determinants of human capital choices.

This paper is organized as follows. We provide an overview of the South Asian and Pakistani education systems in Section II. Section III outlines a model of school choice. Section IV describes the study design and data collection methodology. We examine heterogeneity in subjective beliefs about earnings and other school-specific outcomes and stated school choice in Section V. Section VI reports estimates from a structural lifecycle utility model of school choice, while Section VII presents our policy experiments. Finally, Section VIII concludes.

\section{The Higher Education System in South Asia and Pakistan}

The higher education system is organized similarly across South Asia, with flagship universities at the top of the hierarchy and lower-tier universities absorbing remaining demand (Barack 2014). The soaring demand for higher education has led to the growth of private universities since the mid-1980s (notably in India, Afghanistan, Bangladesh, and Pakistan), accompanied with a shift of the costs of tuition away from the state and onto students, and uneven quality of education.

In Pakistan, this transition is already well under way: dependence on public funding is limited and universities are increasingly funded through fees and commercial ventures. Forty-five percent of the 138 Pakistani universities are private. ${ }^{6}$ In addition to the recognized private institutions, a large number of illegal private universities operate throughout the country. Both public and private universities have their own entrance exams that are based on the SAT. Colleges may also base admission decisions on the Intermediate/Higher Secondary School Examination and/or a personal interview. Access to higher education is still limited, though: in 2011, the enrollment rate for students between ages 17 and 23 was 5.1 percent (Higher Education Commission Pakistan 2012).

Another feature across South Asia is the possibility to acquire higher education outside the conventional university system, in madrassas (Islamic religious schools). The madrassas in Muslim South Asia teach a curriculum known as Dars-i-Nizami, which runs from 7 to 9 years after the completion of the elementary level and covers subjects such as (Arabic) grammar, rhetoric, Islamic history, and mathematics. This certification is recognized

${ }^{6}$ This rate is between that of Bangladesh and Afghanistan (both at 62 percent) and India (33 percent) (Barack 2014). 
to be equivalent to a bachelor's or master's degree by the Pakistani Ministry of Education. A key feature of madrassas is that they are generally free; usually they do not have any entrance exams either. Estimating madrassas' enrollment in Pakistan, where 97 percent of the population is Muslim, is challenging because fewer than a third are registered (Rashid 2000). However, Ahmad (2004) estimates that there are about 6,000 (secondary and higher level) madrassas, educating about 600,000 students.

Our study focuses on three types of institutions that represent distinct parts of the higher education spectrum in Pakistan. At one end, we have Western-style universities that are similar to American colleges. They provide a liberal arts curriculum, classes are taught in English, and they have mixed-gender campuses. These private institutions charge high tuition and fees and cater primarily to wealthy students. Islamic universities, which are somewhere in the middle of the spectrum, provide a liberal arts curriculum combined with Islamic teachings and courses. These universities have segregated campuses for males and females and classes are taught in Arabic or English. These institutions tend to be public and, therefore, are accessible to low and middle income groups. Finally, at the other end of the spectrum are madrassas, which are generally free and are believed to offer a viable alternative for families that are unable to afford expensive schools (Singer 2001). Madrassas usually do not impart any vocational training, and most of their graduates go on to work in the religious sector.

While returns to schooling are high in a developing-country context such as Pakistan (Jaffry, Ghulam, and Shah 2007), the returns do differ by the type of school, with lower returns associated with public schooling (relative to private) and with Islamic education (Berman and Stepanyan 2004; Asadullah 2009). ${ }^{7}$

\section{Model}

This section develops a simple model of school choice. A student $i$ lives for $T+1$ periods. Prior to period $t=0$, student $i$ chooses a school $s$ where he enrolls. In period $t=0$, he enrolls in school $s$ to acquire education. Within period $t=0$, he can decide to drop out from school $s$ or graduate from school $s$. In period $t=1$, he enters the labor market where he stays till period $t=1, \ldots, T$. In our setup, the student's most important decisions are (i) the choice of school and (ii) whether to drop out once enrolled in a school. These are important not only because they affect the stream of future earnings (and thus consumption) but also because of the following three individual- and school-specific factors that the student values when in school: $a_{i s}^{1}$, whether the school's teachings

\footnotetext{
7 Data from the late 1970 s, however, show that unemployment was typically low after graduating from a madrassa (Ahmad 2004).
} 
are consistent with $i$ 's ideology; $a_{i s}^{2}$, whether his parents approve of the school; and $a_{i s}^{3}, i$ 's graduation rank at the time of graduation from the school. These school-specific nonpecuniary factors are only enjoyed by the student if he does not drop out from the school. In addition, student $i$ incurs a moving cost $\delta$ if the school he enrolls in is located in a town different from the one he currently resides in, which is indicated by $l_{i s}$. This moving cost is incurred as soon as he enrolls in school $s$, irrespective of whether he drops out. We further assume that student $i$ has a psychic cost $\Psi_{i}$ from dropping out of a school.

Our main interest is to understand student $i$ 's school choice prior to time $t=0$. We start by defining $U_{i s}^{g}$, the utility of graduating from school $s$ once enrolled, and $U_{i s}^{d}$, the utility of dropping out from school $s$ once enrolled. For tractability, we assume that the utility functions are additively separable, linear in the school outcomes and location, and logarithmic in consumption. They are given by

$$
\begin{gathered}
U_{i s}^{d}=\theta \sum_{t=0}^{T} \beta^{t} \ln \left(c_{i t}^{d}\right)+\delta l_{i s}+\Psi_{i}+\gamma_{s}, \\
U_{i s}^{g}=\theta \sum_{t=0}^{T} \beta^{t} \ln \left(c_{i t}^{g}\right)+\sum_{j=1}^{3} \alpha_{j} a^{j}+\delta l_{i s}+\eta_{s}+\gamma_{s},
\end{gathered}
$$

where $\theta$ is the utility value of $\log$ consumption, $\beta$ is the time preference discount factor, $c_{i t}^{j}$ is $i$ 's consumption at time $t$ (for $j=\{g, d\}$, where $g$ denotes graduate and $d$ dropout), $\alpha_{j}$ is the utility value of outcome $a_{i s}^{j}$, and $\gamma_{s}$ and $\eta_{s}$ are school-specific constants. The $\eta_{s}$ 's reflect unobservable school-

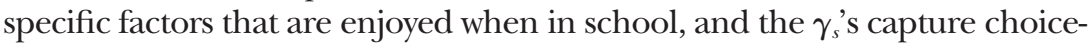
specific unobservable factors that affect lifetime utility regardless of the dropout decision.

Consistent with the lack of well-functioning credit markets in Pakistan, there is no borrowing or lending possible, so student $i$ will consume his earnings at every period from $t=1$ to $T$. Let $y_{i t}^{j}$, for $j=\{d, g\}$, denote his period $t$ earnings. At time $t=0, i$ needs to finance his schooling out of his parent's allowance $y_{i 0}$ and he faces expected school-specific fees $F_{i s}$ that need to be paid up-front if he enrolls in school $s$. If he drops out, his fees will be reimbursed within period $t=0$.

His per-period budget constraints are therefore given by

$$
\begin{gathered}
c_{i 0}^{d} \leq y_{i 0}, \\
c_{i 0}^{g}+F_{i s} \leq y_{i 0}, \\
c_{i t}^{h}=y_{i t}^{h} \quad \text { for } t=1 \text { to } T, h=\{g, t\} .
\end{gathered}
$$

A key feature of the model is that at the time of choosing school $s$, the student faces uncertainty about the school-specific factors as well as 
lifetime earnings associated with each choice. For example, $i$ may be unsure about the type of teaching taking place in a school, his ability compared to other students, and his future labor market earnings if he were to graduate or drop out from a particular school. Student $i$ further expects to receive new information shocks $\left\{\xi_{i s}^{j}\right\}_{j=\{d, g\}}$ with mean $\mu_{i}^{\xi}$ once he is enrolled that will inform his dropout decision. These information shocks are individual-, school-, and dropout decision-specific and are assumed by the students to be additive to the utility functions given in equations (1) and (2). They are not realized at the time of choosing a school $s$ prior to time $t=0$, but will be realized at $t=0$ by the time the student decides whether to drop out. Based on the information available to him prior to time $t=0$, student $i$ possesses a distribution of beliefs $G_{i s}$ of all these events, conditional on each school $s$. Using the law of iterated expectations, we now define student $i$ 's subjective expected lifetime utility associated with choosing school $s$ prior to time $t=0$ as follows:

$$
\begin{aligned}
E_{i}\left(U_{i s}\right)= & P_{i s}(d) E\left(U_{i s}^{d}+\xi_{i s}^{d}\right)+\left[1-P_{i s}(d)\right] E\left(U_{i s}^{g}+\xi_{i s}^{g}\right)+\varepsilon_{i s} \\
= & P_{i s}(d) \int\left(U_{i s}^{d}+\xi_{i s}^{d}\right) d G_{i s} \\
& +\left[1-P_{i s}(d)\right] \int\left(U_{i s}^{g}+\xi_{i s}^{g}\right) d G_{i s}+\varepsilon_{i s},
\end{aligned}
$$

where $\varepsilon_{i s}$ is a random term which is individual-and school-specific, observable to student $i$ at the time of choosing school $s$ but not to the econometrician. Because of the separability assumption of the utility, only marginal beliefs matter in writing the subjective expected utility. We denote by $P_{i s}\left(a^{j}\right)$ the marginal probability about the binary factors $a_{i s}^{j}$ for $j=$ $\{1,2\}$, and by $E_{i s}\left(a^{3}\right) i$ 's expected graduation rank if he enrolls in school $s$. Regarding future earnings, besides the uncertainty about graduating from school $s$, the student is uncertain about whether he would find a job, and about what his earnings would be for each of these scenarios. Student $i$ therefore possesses the following school-specific subjective probabilities: the probability $P_{i s}$ ( job $\mid d$ ) of finding a job if he drops out after enrolling in school $s$ and the probability $P_{i s}($ job $\mid g)$ of finding a job if he graduates from school $s$ after enrolling in school $s$. He also possesses subjective expectations $Y_{i s j t}$ about his labor earnings at time $t$ if he enrolls in school $s$ and either drops out $(j=d)$ or graduates $(j=g) .{ }^{8}$ In case of unemployment, earnings are assumed to be a fraction $r$ of the earnings if

\footnotetext{
${ }^{8}$ For ease of exposition, we initially assume that there is no uncertainty in earnings conditional on employment. We relax this assumption later in the empirical analysis. Note that the specification assumes that students cannot transfer between schools, and that students enter the labor market after either graduating or dropping out of school.
} 
employed. We assume for simplicity that $P_{i s}(\mathrm{job} \mid d)$ and $P_{i s}(\mathrm{job} \mid g)$ are time invariant.

Student $i$ 's subjective expected lifetime utility of attending school $s$ given in equation (4) can then be written as

$$
\begin{aligned}
E_{i}\left(U_{i s}\right)=[ & \left.1-P_{i s}(d)\right]\left[\sum_{j=1}^{2} \alpha_{j} P_{i s}\left(a^{j}\right)+\alpha_{3} E_{i s}\left(a^{3}\right)+\eta_{s}\right] \\
& +\theta\left\{\left[1-P_{i s}(d)\right] \ln \left(y_{i 0}-F_{i s}\right)+P_{i s}(d) \ln \left(y_{i 0}\right)\right\} \\
& +\theta \sum_{t=1}^{T} \beta^{t}\left(P_{i s}(d)\left\{P_{i s}(\mathrm{job} \mid d) \ln \left(Y_{i s d t}\right)+\left[1-P_{i s}(\mathrm{job} \mid d)\right] \ln \left(r Y_{i s d t}\right)\right\}\right. \\
& \left.+\left[1-P_{i s}(d)\right]\left\{P_{i s}(\mathrm{job} \mid g) \ln \left(Y_{i s g t}\right)+\left[1-P_{i s}(\mathrm{job} \mid g)\right] \ln \left(r Y_{\text {isgt }}\right)\right\}\right) \\
& +P_{i s}(d) \Psi_{i}+\delta l_{i s}+\gamma_{s}+\mu_{i}^{\xi}+\varepsilon_{i s} .
\end{aligned}
$$

At the time of choosing which school to enroll in (i.e., prior to time $t=0)$, student $i$ also formulates the subjective probability $P_{i s}(d)$ of dropping out from $s$. It is the probability that his subjective expected utility of dropping out is strictly larger than his subjective expected utility of graduating. The information shocks $\left\{\xi_{i s}^{j}\right\}_{j=\{d, g\}}$ are not realized at the time of formulating the subjective probability of dropping out but will be at the time of the dropout decision, while the outcomes $\left\{a^{j}\right\}_{j=1}^{3},\left\{y_{i t}^{d}\right\}_{t=1}^{T},\left\{y_{i t}^{g}\right\}_{t=1}^{T}$ will still not be realized. Let $H_{i s}$ denote the subjective distribution of beliefs about the outcomes and $F_{\xi}$ be the subjective distribution of $\xi_{i s}^{g}-\xi_{\text {is }}^{d}$ prior to time $t=0$. Student $i$ 's subjective probability of dropout if he enrolls in school $s$ is therefore given by

$$
\begin{aligned}
P_{i s}(d)=P( & \left(\int U_{i s}^{d} d H_{i s}+\xi_{i s}^{d}>\int U_{i s}^{g} d H_{i s}+\xi_{i s}^{g}\right) \\
=F_{\xi} & \left(\theta\left[\ln \left(y_{i 0}\right)-\ln \left(y_{i 0}-F_{i s}\right)\right]\right. \\
& -\left[\sum_{j=1}^{2} \alpha_{j} P_{i s}\left(a^{j}\right)+\alpha_{3} E_{i s}\left(a^{3}\right)\right]-\eta_{s} \\
& \left.+\theta \sum_{t=1}^{T} \beta^{t}\left\{\ln \left(Y_{\text {isdt }}\right)-\ln \left(Y_{\text {isgt }}\right)+\ln r\left[P_{i s}(\mathrm{job} \mid g)-P_{i s}(\mathrm{job} \mid d)\right]\right\}+\Psi_{i}\right) .
\end{aligned}
$$

Because student $i$ cannot borrow to finance the school cost and because fees need to be paid up-front before the dropout decision, student $i$ will choose the school $s$ that maximizes his subjective expected utility (5) among the set of schools for which the period-zero budget constraint $c_{i 0}+F_{i s} \leq y_{i 0}$ is not violated, that is, schools for which the fees do not 
exceed parents' allowance. Let $S_{i}$ denote the set of schools that satisfy $i$ 's period-zero budget constraint. Student $i$ solves $\max _{s \in S_{i}} E_{i}\left(U_{i s}\right)$, subject to the budget constraint (3) and equation (6).

The goal of the empirical analysis is to estimate the parameters of the utility function (up to scale). For this purpose, it is only necessary to have information on the expectations agents hold at the time they make their choice, since those are the beliefs relevant for the decision-making process. Identification of the empirical choice model is discussed in Section VI. As mentioned above, we relax the conventional approach of assuming a mapping between beliefs and realizations of outcomes (such as earnings and ability) for the school that is chosen as well as the schools that are not chosen, and instead collect data on students' subjective expectations about school-specific outcomes.

Importantly, in our analysis of school and dropout choice, we model some expectations as a function of the preference parameters (i.e., the subjective probability of dropout), while others are taken as given by the respondents (e.g., the subjective probability of a school's teaching being consistent with ideology). Whether expectations relate to the structural preference parameters depends on the nature of the event over which expectations are formed. Conceptually, we can classify the expectations relevant to our model as follows: (i) expectations over a controlled event or future choice: the individual has full control over the event/choice (for example, whether to drop out or not); (ii) expectations over uncontrolled events: the individual has no control over the event and heterogeneity in expectations depends on individual-specific beliefs regarding the underlying processes and information sets (e.g., the school's ideology, parental approval); and (iii) expectations over semicontrolled events: the individual has direct control over some determinants of the event but not others, and not over the event itself (e.g., graduation rank, earnings, employment). Expectations over future choices depend on structural preference parameters (in the same way that actual choices do), while expectations over uncontrolled events do not. ${ }^{9}$

\section{Study Design}

This section describes our sample, data collection methodology, and survey design.

\footnotetext{
${ }^{9}$ In our analysis, we do not model expectations over semicontrolled events. In reality, expectations over semicontrolled events such as graduation rank and labor market outcomes may be partially affected, e.g., by the student's effort at university or during the job search. Thus, they might depend on the structural preference parameters as well. Conditional on effort, they are, however, similar to expectations over uncontrolled events. We abstract from effort decisions in our analysis (implicitly assuming that those decisions are policy invariant) and focus on school and dropout choices.
} 


\section{A. The Sample}

Our study was conducted in two Western-style universities, one Islamic university (IU), and four madrassas (M), all located in Islamabad/Rawalpindi and Lahore, between May and October $2010 .^{10}$ The Islamabad/Rawalpindi metropolitan area is the third largest in the country with a population of about 4.5 million, and Islamabad is Pakistan's capital. Lahore is the capital of the Punjab province and the country's second largest city with about 10 million inhabitants.

The institutions in our sample are among the five largest and bestregarded institutions in the relevant category in each city. Among all the institutions we contacted, one university and one madrassa declined participation. We sampled the higher level students in the four madrassas since they are similar in age to university students and are pursuing the madrassa equivalent of a bachelor's degree. Though participation was voluntary, almost everyone in the madrassas participated in the study. At the other institutions, a random sample of students was selected to participate based on a listing of students provided by the registrar's office. The average response rate at the universities was about 70 percent. Our analytical sample consists of 2,149 male students. ${ }^{11}$

The two Western-style universities in our sample differ in their selectivity, reputation, and cost. We term the more expensive, selective, and reputable university "Very Selective University" (VSU) and the other simply "Selective University" (SU). Since the four madrassas in our sample are similar in terms of their student body composition, we pool the data across the four madrassas $(\mathrm{M})$. We discuss the data collection procedure in appendix A.

\section{B. Sample Characteristics}

Table 1 presents the characteristics of students at the four institution groups. There is substantial sorting in terms of observables into these institutions. As we move across the columns from VSU toward M in table 1, the average socioeconomic characteristics deteriorate. For example, the monthly parental income of VSU students is nearly twice that of SU students, about 4.5 times that of students at IU, and 10 times that of M students. Similar patterns emerge with regard to parents' education and asset ownership: the proportion of students with at least one college-educated parent declines from 89 percent for VSU students to about 13 percent

\footnotetext{
${ }^{10}$ We excluded public secular universities from the study, since they tend to be large and have separate campuses for each of the broad fields of study. Surveying a representative set of students in such schools would not have been feasible.

${ }^{11}$ We interviewed 2,347 male students. For the empirical analysis, we exclude respondents reporting beliefs (school costs and expected earnings) below the 0.5 th percentile and above the 99.5 th percentile of the respective distributions. The demographic characteristics of the full sample are similar to those of the analytical sample.
} 
TABLE 1

Sample Characteristics

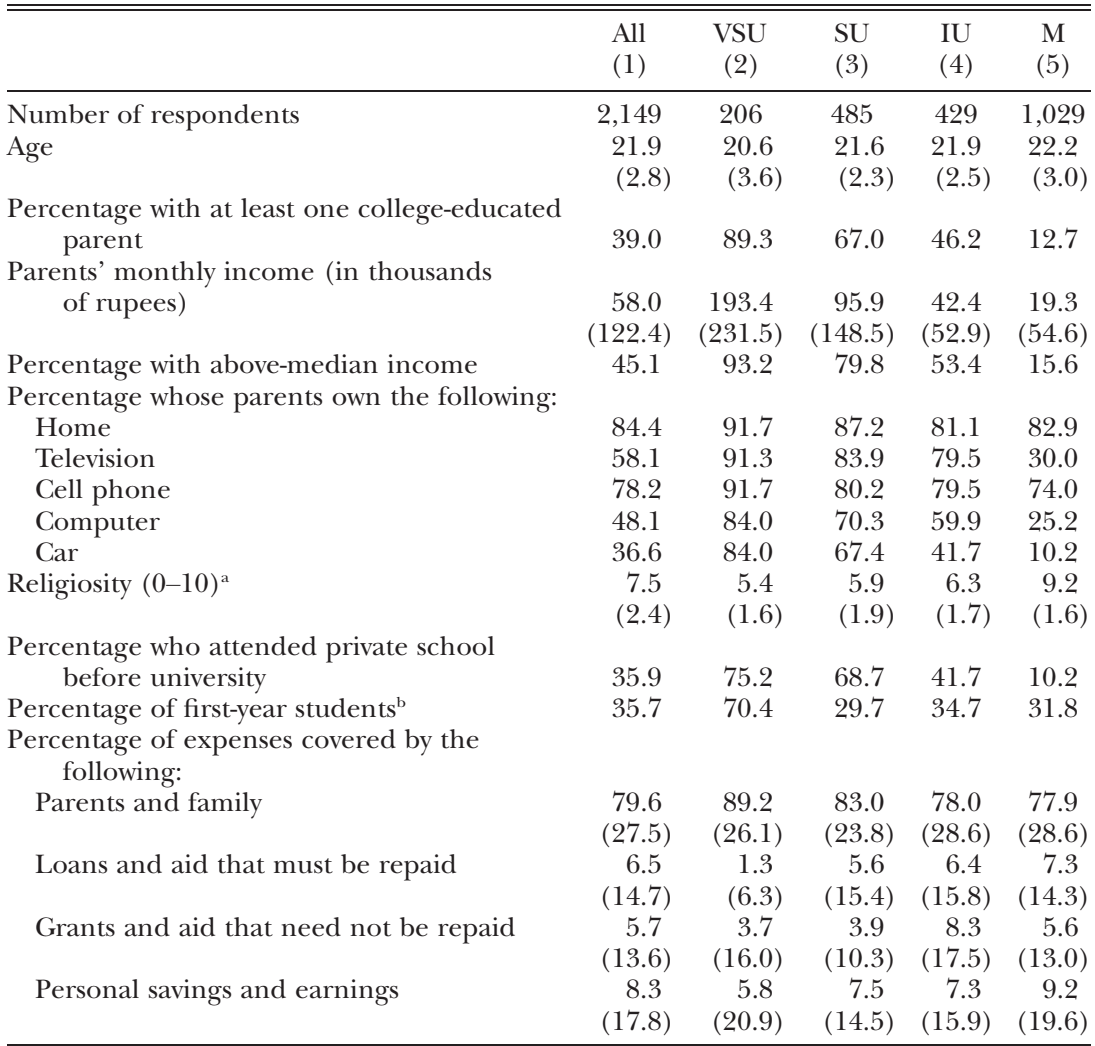

Note.-Table reports the mean of the continuous variables, with standard deviations in parentheses.

a Self-reported religiosity on a scale of zero (not religious at all) to 10 (very religious).

b An M student is classified as being first-year if he is 20 years old or younger.

for $\mathrm{M}$ students. The students also differ in the type of high school they attended, with 75 percent of the VSU students having attended a private school compared to only 10 percent of the M students.

Students from the various groups also report different levels of selfreported religiosity. Students were asked to rate how religious they considered themselves on a scale from 0 (not religious at all) to 10 (very religious). As one may expect, religiosity increases as we move across the columns of table 1: The average religiosity is 5.4 for VSU students and 9.2 for M students. There is also variation in the school year of students, with nearly a third of our sample being in the first year. ${ }^{12}$

${ }^{12}$ Given that madrassas tend to admit students starting at young ages, only a small proportion (1.5 percent) of $\mathrm{M}$ students are in the first year in our sample. Throughout the paper, we classify an M student as being first year if he is 20 years old or younger. We find that 31.8 percent of $\mathrm{M}$ students fall into that group. 
Regarding the financing of educational expenses, table 1 shows that the education expenses are covered largely by parents and family ( 80 percent, on average). We also see that $\mathrm{M}$ students have a higher reliance on loans/ aid that need to be repaid, and on personal savings/earnings.

\section{Description of Expectations and Preferences}

This section describes students' choice set, their stated school choice, and the subjective expectations data. Appendix A presents the exact wording of some relevant questions from the survey instrument.

\section{A. Stated Choice and Choice Set Data}

For the purposes of understanding school choice, we asked respondents to consider the following hypothetical situation: "The following question asks you to consider some hypothetical enrollment choices assuming that you did not start your degree at your current institution. Suppose that you were guaranteed admission in the following: the bachelor's degree program at Very Selective University, the bachelor's degree program at Selective University, the bachelor's degree program at Islamic University, the Alim course at Madrassa-City 1, and the Alim course at Madrassa-City 2. Suppose further that you were guaranteed admission only at those five institutions. We ask you to think about where you would choose to go."

Students were then asked various questions about where they would choose to enroll. ${ }^{13}$ First, they were asked to rank the institutions belonging to the constrained choice set according to their preference for enrolling in them. The set of schools that a student can afford to attend financially (i.e., the constrained choice set $S_{i}$ from Sec. III) is determined as follows: Students were asked the maximum education-related expenses that they and their family can cover, and the perceived net costs for each of the five institutions. Schools for which the perceived net costs were at or below the reported maximum expenses that the student (and their family) can pay are then defined as being in the student's constrained choice set. Since the student's current institution was included in the list of schools, the student's constrained choice set included at least their current school.

Next, students were told to consider a scenario in which all expenses would be covered: "As before, suppose that you are guaranteed admission

\footnotetext{
${ }^{13}$ In the questionnaire, students saw the actual name of each of the institutions. The school the student was currently enrolled in was included in the list. Depending on the city in which the student currently resides, two or three of the five schools were located in the student's current city. As mentioned above, the institutions we chose are among the five largest in their relevant category in their respective city. However, to make sure that students were familiar with them, we provided students with a two-sentence description of each school. City 1 refers to a fixed city that was mentioned to the respondents.
} 
in each of these five schools, and that you are provided with financial aid such that all your expenses (tuition, boarding, room, etc.) are paid for at each institution." In this scenario, all five schools are part of all students' choice set. This is the unconstrained choice set. Students were then asked to rank all five institutions in terms of their preference for enrolling in them. Note that in both scenarios above, students are told that they are guaranteed admission into each of the institutions. Therefore, the hypothetical situation abstracts from any concerns related to admissibility.

We describe below the stated choice data. To facilitate the reading of the tables and description of results, we use the acronyms VSU, SU, IU, and $\mathrm{M}$ when referring to the schools in which students are currently enrolled, and we use the full names (Very Selective University, Selective University, Islamic University, and Madrassa City-1 or Madrassa-City 2) when referring to the hypothetical set of schools that students could enroll in.

\section{Constrained Choice}

Panel A of table 2 shows the statistics related to the constrained choice set. Only about 43 percent of the students report being able to afford attending Very Selective University. On the other hand, 94 percent of students report being able to cover the costs of attending madrassas. This is consistent with the actual high costs of attending the universities, and practically no tuition at madrassas (as also indicated in col. 6 of table 5, which reports cost). As we move across the columns, the proportion of students who can attend each school type generally decreases; this variation is quite sensible since table 1 shows that socioeconomic characteristics of students deteriorate moving from VSU to M. ${ }^{14}$

Panel A of table 2 also shows the proportion of students who rank each of the schools as their top choice. We see that Very Selective University is ranked highest by 84 percent of VSU students, 15 percent of SU students, 9 percent of IU students, and less than 1 percent of $\mathrm{M}$ students. This variation is likely a result of either differences in preferences and/or feasibility of the choice. Only 45 percent of SU students say they can afford Very Selective University. By construction, therefore, at least 55 percent of SU students could not have ranked Very Selective University the highest. In fact, we see that the median number of schools ranked by $\mathrm{M}$ students is only two (out of five): the median M student reports being able to afford only the two madrassas (and hence only ranks them). Similarly, the median IU and SU students rank only four schools, while the median

${ }^{14}$ Table A1 in the online appendix further shows that there is sensible variation in the affordability of the various schools by various demographic characteristics. For example, 58 percent of students from the highest tercile of parents' income report that Very Selective University is in their constrained choice set, versus only 27 percent of students from the lowest tercile. 
TABLE 2

Ranking of Schools and Credit Constraints

\begin{tabular}{|c|c|c|c|c|c|}
\hline & $\begin{array}{l}\text { All } \\
\text { (1) }\end{array}$ & $\begin{array}{c}\text { VSU } \\
(2)\end{array}$ & $\begin{array}{l}\text { SU } \\
(3)\end{array}$ & $\begin{array}{l}\text { IU } \\
(4)\end{array}$ & $\begin{array}{l}M \\
(5)\end{array}$ \\
\hline & \multicolumn{5}{|c|}{ A. With School Costs } \\
\hline \multicolumn{6}{|l|}{ Proportion who can afford the school: } \\
\hline Very Selective University & .43 & 1.00 & .45 & .41 & .30 \\
\hline Selective University & .60 & .92 & 1.00 & .66 & .31 \\
\hline Islamic University & .65 & .90 & .79 & 1.00 & .39 \\
\hline Madrassa-City 1 & .94 & .97 & .96 & .96 & .91 \\
\hline Madrassa-City 2 & .94 & .95 & .98 & .95 & .92 \\
\hline$\chi^{2}$ test & .000 & .000 & .000 & .000 & .000 \\
\hline \multicolumn{6}{|l|}{ Proportion who rank school the highest: } \\
\hline Very Selective University & .13 & .84 & .15 & .09 & .003 \\
\hline Selective University & .12 & .06 & .46 & .07 & .002 \\
\hline Islamic University & .20 & .05 & .21 & .70 & .01 \\
\hline Madrassa-City 1 & .24 & .04 & .09 & .09 & .42 \\
\hline Madrassa-City 2 & .30 & .01 & .09 & .05 & .56 \\
\hline \multicolumn{6}{|l|}{ Number of schools ranked: } \\
\hline Mean & 3.5 & 4.6 & 4.1 & 3.9 & 2.8 \\
\hline Median & 4 & 5 & 4 & 4 & 2 \\
\hline \multirow[t]{2}{*}{ school from current school } & .27 & .13 & .54 & .29 & .15 \\
\hline & \multicolumn{5}{|c|}{ B. No School Costs } \\
\hline \multicolumn{6}{|l|}{$\begin{array}{l}\text { Proportion who rank school the highest } \\
\text { conditional on no school costs: }\end{array}$} \\
\hline Very Selective University & $.37 * * *$ & .79 & $.72 * * *$ & $.59 * * *$ & $.02 * * *$ \\
\hline Selective University & $.04 * * *$ & .08 & $.09 * * *$ & $.04 *$ & $.01 * * *$ \\
\hline Islamic University & $.15^{* * *}$ & .06 & $.10^{* * *}$ & $.31 * * *$ & $.13 * * *$ \\
\hline Madrassa-City 1 & $.20 * * *$ & .03 & $.05^{*}$ & $.06^{*}$ & $.37 *$ \\
\hline Madrassa-City 2 & $.24 * * *$ & $.04 *$ & $.03 * * *$ & $.01 * * *$ & $.47 * * *$ \\
\hline \multicolumn{6}{|l|}{ Proportion who switch highest-ranked } \\
\hline school from panel A to panel B & .41 & .31 & .65 & .59 & .24 \\
\hline Number of students & 2,149 & 206 & 485 & 429 & 1,029 \\
\hline
\end{tabular}

Note.-We conduct a $\chi^{2}$ test for the equality of proportions who rank a school highest conditional on school costs, and the proportion who rank the school highest conditional on no costs. Significance denoted by asterisks on proportions reported in panel B.

* Significant at the 10 percent level.

*** Significant at the 1 percent level.

VSU student ranks five schools. This indicates that affordability plays an important role in students' choices. ${ }^{15}$

${ }^{15}$ A notable observation in panel A of table 2 is that 27 percent of the students do not rank their own school as their first choice. One reason for a different choice may be the fact that some students were unable to gain admission to their preferred school. Other reasons include the possibility that students have learned new information about the various schools since they made their choice (see Stinebrickner and Stinebrickner [2014a, 2014b] for the role of learning). Likewise, the switching behavior may arise if parents were instrumental in students' actual choice, which may not be reflected in the hypothetical choice. We discuss this in Sec. III. 
2. Unconstrained Choice

Panel B of table 2 reports the unconstrained choice of the students. Comparing column 1 in panel B to that in panel A, we see that the proportion of students assigning the highest rank to VSU triples to 37 percent, while the proportions for the other schools are lower (all these proportions are significantly different from their corresponding values in panel $\mathrm{A}$ at the 1 percent level, using a $\chi^{2}$ test).

Two patterns are of note in this panel. First, we see that among SU and IU students, the proportion who assign the highest rank to Very Selective University is substantially higher than the proportion who rank their current institution the highest. Absent school costs and assuming guaranteed admissions, the majority of SU and IU students (72 percent and 59 percent, respectively) would enroll in Very Selective University. Second, while the increase in M students who rank Very Selective University is small (from 0.3 percent to 2 percent), there is a large jump in the proportion of students who now rank Islamic University the highest (13 percent compared to 1 percent in the presence of school costs).

The panel also reports the proportion of students who switch their topranked school with the waiver of costs: we see that 41 percent of the students would choose a different school, were it not for school costs. This suggests that financial constraints may play an important role in school choice.

\section{B. Expectations about Future Earnings}

Students were asked two sets of earnings expectations, conditional on each school. First, respondents were asked about their own age 30 earnings conditional on graduating as well as dropping out from each of the schools (and conditional on working). Students were also asked about the probability of being employed conditional on graduating as well as dropping out from each of those schools. These expectations are the relevant ones for their decision-making process (see Sec. III). We also collected students' beliefs about the average earnings at age 30 of a typical working male graduate of each of these institutions. We refer to these as beliefs about population earnings. These allow us to investigate whether students are aware of the differential labor market returns associated with each of the schools. ${ }^{16}$ We describe each of these expectations in turn.

\footnotetext{
${ }^{16}$ Such an analysis is not possible for self earnings beliefs since those may differ from objective measures of earnings of current graduates for several reasons. Respondents may, e.g., have private information about themselves that justifies having different expectations, or they may think that future earnings distributions will differ from the current ones.
} 
1. Expectations about Population Earnings

Table 3 shows the mean, median, and standard deviation of respondents' beliefs about the average earnings of current age 30 graduates from each of the schools. Each column shows the beliefs held by students from a given institution. In column 1, which pools students from all institutions, we see that the mean belief about monthly population earnings varies between Rs. 17,100 for madrassa graduates to Rs. 45,900 for Very Selective University graduates. Selective University and Islamic University graduates are believed to have earnings that are somewhere in between. Median earnings beliefs also follow a similar pattern. There is, however, considerable heterogeneity in beliefs as indicated by the large standard deviation in beliefs about the population means. For example, for Very Selective University graduates, the overall median earnings are Rs. 40,000, while the 10th percentile is Rs. 10,000 and the 90 th percentile is Rs. 86,000. The table also reports the response rates: they are above 99 percent, indicating that missing data are not an issue.

Columns $2-5$ of the table present the average population beliefs, as reported by students currently enrolled in the four school types. The levels of earnings reported by students in the four school types differ quite

TABLE 3

Population Beliefs: Perceived Age 30 Monthly Earnings (in Thousands of Rupees) of Male Graduates of Different School Types

\begin{tabular}{lcccccc}
\hline \hline & $\begin{array}{c}\text { All } \\
(1)\end{array}$ & $\begin{array}{c}\text { VSU } \\
(2)\end{array}$ & $\begin{array}{c}\text { SU } \\
(3)\end{array}$ & $\begin{array}{c}\text { IU } \\
(4)\end{array}$ & $\begin{array}{c}\text { M } \\
(5)\end{array}$ & $\begin{array}{c}\text { Objective Value }^{\text {a }} \\
(6)\end{array}$ \\
\hline Very Selective University & 45.9 & 43.9 & 67.9 & 60.3 & 29.8 & 38.8 \\
& {$[40.0]$} & {$[40.0]$} & {$[55.0]$} & {$[50.0]$} & {$[25.0]$} & {$[41.3]$} \\
& $(46.0)$ & $(29.9)$ & $(69.6)$ & $(37.3)$ & $(28.3)$ & $(10.9)$ \\
Selective University & 36.0 & 40.4 & 44.4 & 42.2 & 28.6 & 30.9 \\
& {$[30.0]$} & {$[35.0]$} & {$[35.0]$} & {$[40.0]$} & {$[20.0]$} & {$[30.3]$} \\
& $(49.3)$ & $(23.3)$ & $(75.4)$ & $(30.3)$ & $(42.4)$ & $(11.2)$ \\
Islamic University & 34.0 & 34.2 & 45.8 & 43.4 & 24.5 & 26.0 \\
& {$[30.0]$} & {$[30.0]$} & {$[35.0]$} & {$[40.0]$} & {$[20.0]$} & {$[25.0]$} \\
Madrassa-City 1 & $(38.8)$ & $(18.2)$ & $(66.6)$ & $(24.3)$ & $(23.1)$ & $(3.6)$ \\
& 17.1 & 29.0 & 21.6 & 18.2 & 12.1 & 9.4 \\
& {$[15.0]$} & {$[20.0]$} & {$[20.0]$} & {$[17.0]$} & {$[10.0]$} & {$[8.8]$} \\
Madrassa-City 2 & $(16.9)$ & $(21.9)$ & $(18.7)$ & $(10.6)$ & $(15.0)$ & $(1.8)$ \\
& 17.6 & 28.5 & 21.6 & 18.8 & 13.0 & 15.0 \\
Number of respondents & {$[15.0]$} & {$[25.0]$} & {$[20.0]$} & {$[18.0]$} & {$[10.0]$} & {$[15.0]$} \\
Response rate & $(16.1)$ & $(19.4)$ & $(12.9)$ & $(11.8)$ & $(16.6)$ & $(4.1)$ \\
\hline
\end{tabular}

NoTE.-Medians are reported in square brackets and standard deviations in parentheses.

a Objective value refers to the survey responses of the administrators of the institutions (four administrators each at VSU, SU, M-City 1, and M-City 2, and three administrators at IU).

b Percentage of responses with no missing data for any variables in the column. 
substantially for each of the five school choices. However, despite differences in levels, beliefs about relative population earnings for the different school types are similar for students enrolled in each of the schools, with students expecting average earnings to be the highest for Very Selective University graduates and the lowest for madrassa graduates.

Columns $1-5$ of table 3 indicate that students expect labor market returns associated with the five schools to differ significantly. A relevant question for policy makers is whether these perceptions are accurate. To investigate that, one would need to know the "true" population earnings. However, these data do not exist, since none of these schools collect data on their graduates' labor market outcomes. In order to shed light on how well informed students are, we instead conducted a poll of a handful of administrators at each of these schools and asked them about the average earnings of their recent graduates. ${ }^{17}$ These statistics are reported in column 6 of the table. While these data are based on small sample sizes and on perceptions of administrators, they are still informative. The median earnings beliefs of the students (in col. 1) are quite similar to the medians reported by the school administrators. More importantly, both sources of data yield a similar ranking of schools based on earnings.

\section{Expectations about Own Future Earnings}

Panel A of table 4 reports expected age 30 own earnings conditional on graduation. As in table 3 , each column shows the beliefs held by students from a given institution. Pooling all students in column 1, we see that expectations about own earnings follow the same pattern as expectations about population beliefs, with students believing their earnings will be highest if they graduate from Very Selective University and lowest if they graduate from a madrassa. A comparison of column 1 with population beliefs (in col. 1 of table 3 ) shows that expectations about own and population earnings are very similar. We find a significant correlation of .715 between own and population earnings expectations in our sample (Spearman rank; $p=.000)$, suggesting that own earnings expectations are based in part on individuals' beliefs about the population distribution of earnings. This high correlation also suggests that if respondents are misinformed about the distribution of population earnings, they will have biased own earnings expectations. The online appendix describes the heterogeneity in expectations.

Panel B of table 4 shows respondents' own earnings expectations at age 30 conditional on enrolling in each of the schools, but dropping

\footnotetext{
${ }^{17}$ A separate survey was designed for the school administrators. This was filled out by four administrators each at VSU, SU, M-City 1, and M-City 2, and by three administrators at IU.
} 
TABLE 4

Age 30 Self Monthly Earnings Beliefs Conditional ON WORKING (in Thousands of Rupees)

\begin{tabular}{|c|c|c|c|c|c|}
\hline & $\begin{array}{l}\text { All } \\
(1)\end{array}$ & $\begin{array}{l}\text { VSU } \\
(2)\end{array}$ & $\begin{array}{l}\text { SU } \\
(3)\end{array}$ & $\begin{array}{l}\text { IU } \\
(4)\end{array}$ & $\begin{array}{l}\mathrm{M} \\
(5)\end{array}$ \\
\hline & \multicolumn{5}{|c|}{$\begin{array}{l}\text { A. Beliefs about Own Age } 30 \text { Earnings } \\
\text { Conditional on Graduating }\end{array}$} \\
\hline \multirow[t]{3}{*}{ Very Selective University } & 47.3 & 52.0 & 70.1 & 61.1 & 29.8 \\
\hline & {$[40.0]$} & {$[50.0]$} & {$[60.0]$} & {$[50.0]$} & {$[25.0]$} \\
\hline & $(39.6)$ & $(30.5)$ & $(47.4)$ & $(37.6)$ & $(28.5)$ \\
\hline \multirow[t]{3}{*}{ Selective University } & 34.0 & 36.6 & 43.7 & 39.6 & 26.6 \\
\hline & {$[30.0]$} & {$[30.0]$} & {$[35.0]$} & {$[35.0]$} & {$[20.0]$} \\
\hline & $(25.5)$ & $(25.3)$ & $(28.0)$ & $(21.1)$ & $(23.7)$ \\
\hline \multirow[t]{3}{*}{ Islamic University } & 34.3 & 46.5 & 41.8 & 45.2 & 23.8 \\
\hline & {$[30.0]$} & {$[40.0]$} & {$[35.0]$} & {$[40.0]$} & {$[20.0]$} \\
\hline & $(26.5)$ & $(29.0)$ & $(27.8)$ & $(28.7)$ & $(19.4)$ \\
\hline \multirow[t]{3}{*}{ Madrassa-City 1} & 15.9 & 21.0 & 22.0 & 17.8 & 11.1 \\
\hline & {$[15.0]$} & {$[20.0]$} & {$[20.0]$} & {$[15.0]$} & {$[8.5]$} \\
\hline & $(12.5)$ & $(13.7)$ & (13.1) & $(10.7)$ & $(10.6)$ \\
\hline \multirow{3}{*}{ Madrassa-City 2} & 17.1 & 27.8 & 21.9 & 18.8 & 12.0 \\
\hline & {$[15.0]$} & {$[20.0]$} & {$[20.0]$} & {$[18.0]$} & {$[10.0]$} \\
\hline & $(14.3)$ & $(21.5)$ & $(13.5)$ & $(11.5)$ & $(11.4)$ \\
\hline \multirow[t]{2}{*}{ Response Rate $^{\mathrm{a}}$} & 99.6 & 100.0 & 100.0 & 99.5 & 99.4 \\
\hline & \multicolumn{5}{|c|}{$\begin{array}{l}\text { B. Beliefs about Own Age } 30 \text { Earnings } \\
\text { Conditional on Dropping Out }\end{array}$} \\
\hline \multirow[t]{3}{*}{ Very Selective University } & 24.1 & 32.8 & 32.5 & 28.8 & 16.4 \\
\hline & {$[20.0]$} & {$[27.5]$} & {$[30.0]$} & {$[25.0]$} & {$[12.0]$} \\
\hline & $(23.3)$ & $(20.8)$ & $(25.9)$ & $(20.3)$ & $(21.0)$ \\
\hline \multirow[t]{3}{*}{ Selective University } & 19.5 & 29.0 & 22.8 & 20.7 & 15.5 \\
\hline & {$[15.0]$} & {$[25.0]$} & {$[20.0]$} & {$[20.0]$} & {$[10.0]$} \\
\hline & $(18.3)$ & $(17.8)$ & $(18.3)$ & $(12.8)$ & $(19.2)$ \\
\hline \multirow[t]{3}{*}{ Islamic University } & 19.3 & 23.5 & 22.9 & 23.0 & 15.3 \\
\hline & {$[15.0]$} & {$[20.0]$} & {$[20.0]$} & {$[20.0]$} & {$[10.0]$} \\
\hline & $(18.7)$ & $(16.9)$ & $(21.3)$ & $(17.5)$ & $(17.3)$ \\
\hline \multirow[t]{3}{*}{ Madrassa-City 1} & 11.8 & 18.7 & 14.3 & 11.2 & 9.5 \\
\hline & {$[10.0]$} & {$[10.0]$} & {$[10.0]$} & {$[10.0]$} & {$[7.0]$} \\
\hline & (11.6) & $(18.3)$ & $(11.5)$ & $(8.4)$ & $(10.2)$ \\
\hline \multirow[t]{3}{*}{ Madrassa-City 2} & 12.5 & 19.9 & 13.9 & 11.6 & 10.7 \\
\hline & {$[10.0]$} & {$[15.0]$} & {$[10.0]$} & {$[10.0]$} & {$[8.0]$} \\
\hline & $(12.7)$ & $(17.4)$ & $(11.2)$ & $(10.4)$ & $(12.7)$ \\
\hline Response rate $^{\mathrm{a}}$ & 99.4 & 98.5 & 100.0 & 99.3 & 99.3 \\
\hline Number of respondents & 2,149 & 206 & 485 & 429 & 1,029 \\
\hline
\end{tabular}

NoTE.-Medians are reported in square brackets and standard deviations in parentheses.

a Percentage of responses with no missing data for any variables in the column.

out without a degree. On average, respondents report significantly lower earnings (relative to graduating from those schools, as shown in panel A). It is also notable that with the exception of VSU students, respondents on average believe they would earn more were they to enroll and drop out from any of the nonmadrassa schools than if they were to graduate from a madrassa. 
Students, in addition, were asked the employment probabilities at age 30 conditional on both dropping out and graduating-beliefs that are relevant for the decision model described in Section III. These beliefs are shown in table A2 (tables A1-A6 and figs. A1-A5 are available in the online appendix) and described there.

\section{Beliefs about Other School-Specific Factors}

Besides data on labor market outcomes, we also collected data on beliefs of students about other factors that may affect the likelihood of a student choosing that school. The set of factors that we include is as follows: (1) dropping out from the school, (2) alignment of the school's teachings with own ideology, (3) graduation rank, (4) parents' approval of the choice, and (5) monthly net expenses (including tuition). Students were asked for their beliefs about each of these factors, conditional on having enrolled in each of the five different school choices. ${ }^{18}$

Table 5 reports the average beliefs for these outcomes. The top part of the table reports beliefs about the probability of dropping out. We see that students believe they are on average less likely to drop out from the school they are currently enrolled in. This is indicative of sorting into institutions along this dimension. M students, for example, expect to be a third as likely to drop out from a madrassa as from Very Selective University or Selective University. Table 5 is discussed in further detail in the online appendix.

On the whole, analysis of the subjective expectations indicates that students perceive significant differences across the school choices along the various dimensions. Moreover, there is substantial heterogeneity in beliefs of students enrolled within a school, as well as across schools. It is this variation that we exploit in our estimation. Before moving to the empirical analysis, it is worth emphasizing a few benefits of our approach. First, an advantage of eliciting subjective beliefs is that one can also elicit quantitative beliefs about nonpecuniary outcomes (such as parents' approval) data that otherwise are not available. Second, table 5 highlights the advantage of eliciting beliefs for binary outcomes (such as parents' approval) as probabilistic expectations since simple binary responses would be unable to fully unmask this heterogeneity. Third, and perhaps most importantly, table A3 shows that beliefs about the nonpecuniary outcomes are in fact systematically correlated with earnings expectations and perceived employment likelihood. This underscores the point that ignoring the

\footnotetext{
${ }^{18}$ Graduation rank was elicited on a 1-100 scale, where 1 meant the best rank. To provide easier interpretation, we rescaled the graduation rank beliefs such that 100 represents highest rank and 1 represents lowest rank. Other beliefs were elicited as percentages. See app. A.
} 
TABLE 5

Beliefs about Various School-Related Outcomes, across School Choices

\begin{tabular}{|c|c|c|c|c|c|c|}
\hline & $\begin{array}{l}\text { All } \\
(1)\end{array}$ & $\begin{array}{l}\text { VSU } \\
(2)\end{array}$ & $\begin{array}{l}\text { SU } \\
(3)\end{array}$ & $\begin{array}{l}\text { IU } \\
(4)\end{array}$ & $\begin{array}{c}M \\
(5)\end{array}$ & $\begin{array}{c}\text { Objective } \\
\text { Value }^{\mathrm{a}} \\
(6)\end{array}$ \\
\hline \multicolumn{7}{|l|}{ Probability of dropping out: } \\
\hline Very Selective University & 40.7 & 21.4 & 23.5 & 26.8 & 58.5 & \\
\hline Selective University & 40.9 & 43.5 & 17.0 & 28.6 & 56.8 & \\
\hline Islamic University & 30.8 & 52.0 & 23.9 & 12.2 & 37.6 & \\
\hline Madrassa-City 1 & 30.2 & 60.1 & 33.5 & 35.9 & 20.3 & \\
\hline Madrassa-City 2 & 28.4 & 65.3 & 32.3 & 37.1 & 15.7 & \\
\hline Response rate & 99.1 & 97.1 & 99.8 & 98.8 & 99.3 & \\
\hline \multicolumn{7}{|c|}{$\begin{array}{l}\text { Probability of teachings consistent } \\
\text { with ideology: }\end{array}$} \\
\hline Very Selective University & 53.0 & 71.8 & 69.6 & 66.8 & 35.7 & \\
\hline Selective University & 51.4 & 59.4 & 68.2 & 60.5 & 38.1 & \\
\hline Islamic University & 65.2 & 46.4 & 66.6 & 76.9 & 63.3 & \\
\hline Madrassa-City 1 & 67.7 & 31.2 & 53.9 & 56.9 & 86.1 & \\
\hline Madrassa-City 2 & 69.0 & 31.2 & 54.8 & 56.5 & 88.5 & \\
\hline Response rate & 99.8 & 100.0 & 100.0 & 99.8 & 99.6 & \\
\hline \multicolumn{7}{|c|}{ Probability of parents' approval: } \\
\hline Very Selective University & 60.3 & 79.1 & 81.5 & 74.8 & 40.4 & \\
\hline Selective University & 58.1 & 63.5 & 81.7 & 66.8 & 42.2 & \\
\hline Islamic University & 69.5 & 52.3 & 69.5 & 88.7 & 64.8 & \\
\hline Madrassa-City 1 & 64.3 & 27.3 & 48.6 & 50.1 & 85.0 & \\
\hline Madrassa-City 2 & 67.3 & 33.3 & 52.4 & 48.5 & 88.9 & \\
\hline Response rate & 99.6 & 100.0 & 100.0 & 100.0 & 99.2 & \\
\hline \multicolumn{7}{|l|}{ Graduation rank: } \\
\hline Very Selective University & 68.0 & 66.0 & 66.6 & 70.3 & 68.0 & \\
\hline Selective University & 70.2 & 62.5 & 75.3 & 72.5 & 68.3 & \\
\hline Islamic University & 76.4 & 66.0 & 73.2 & 81.1 & 78.1 & \\
\hline Madrassa-City 1 & 74.6 & 54.1 & 67.4 & 67.4 & 85.1 & \\
\hline Madrassa-City 2 & 74.9 & 55.9 & 68.2 & 67.1 & 85.2 & \\
\hline Response rate & 99.7 & 100.0 & 100.0 & 100.0 & 99.4 & \\
\hline \multicolumn{7}{|l|}{$\begin{array}{l}\text { Average monthly net expenses } \\
\text { (in thousands of rupees): }\end{array}$} \\
\hline Very Selective University & 27.6 & 42.2 & 37.2 & 25.3 & 20.9 & 15.5 \\
\hline Selective University & 20.8 & 36.2 & 21.6 & 17.2 & 18.9 & 18.4 \\
\hline Islamic University & 16.9 & 31.1 & 21.6 & 12.6 & 13.6 & 9.3 \\
\hline Madrassa-City 1 & 7.7 & 17.3 & 12.9 & 6.9 & 3.7 & 1.6 \\
\hline Madrassa-City 2 & 7.5 & 17.0 & 10.7 & 7.7 & 3.9 & 1.7 \\
\hline Response rate & 98.9 & 98.1 & 99.8 & 99.3 & 98.4 & \\
\hline Number of respondents & 2,149 & 206 & 485 & 429 & 1,029 & \\
\hline
\end{tabular}

Note.-Table reports the mean statistics.

a Objective value refers to the survey responses of the administrators of the school (four administrators each at VSU, SU, M-City 1, and M-City 2, and three administrators at IU).

nonpecuniary outcomes and subsuming them in the error term in choice models could be problematic. ${ }^{19}$

19 Typically such models are estimated under the assumption that the error term is orthogonal to the other elements of the model; this is likely to yield biased estimates. An alternative to directly incorporating nonpecuniary outcomes in the model-as we do here - is differencing out tastes using exogenous changes in choices and expectations, say through an information experiment (see Wiswall and Zafar 2015). 


\section{Empirical Results}

We first discuss identification of the choice model outlined in Section III and then discuss the estimation results.

\section{A. Identification and Empirical Specifications}

1. Parametric Assumptions on the Utility Functions

We estimate the parameters of the utility function described in Section III using the data described in the previous section. Because of survey time limitations, we were forced to ask a limited set of questions and could not ask respondents to report their earnings for all postgraduation periods. ${ }^{20}$ Since we ask students for expected earnings (conditional on school dropout as well as graduation) and employment probability for age 30 only, we make some functional assumptions about how earnings evolve over the life cycle, and in addition assume that the growth rate of earnings is the same for all schools and graduation outcomes and that unemployment probabilities are time invariant. In particular, we assume that labor earnings in year $t$ grow exponentially at a yearly rate of $g_{t}$ as follows: $Y_{i s h t}=\left(Y_{i s h t-1}\right)^{g_{i t 1}}$ for all schools $s$ and $h=\{d, g\}$ and $t>1$. We can therefore rewrite time $t$ earnings as a function of age 30 earnings as $Y_{\text {isht }}=$ $\left(Y_{i s h 10}\right)^{\kappa_{t}} \cdot{ }^{21}$ Student $i$ 's maximization problem in equation (5) as a function of age 30 labor earnings is then

$$
\begin{aligned}
\max _{s \in S_{i}}( & {\left[1-P_{i s}(d)\right]\left[\sum_{j=1}^{2} \alpha_{j} P_{i s}\left(a^{j}\right)+\alpha_{3} E_{i s}\left(a^{3}\right)+\eta_{s}\right] } \\
& +\theta\left\{\left[1-P_{i s}(d)\right] \ln \left(y_{i 0}-F_{i s}\right)+P_{i s}(d) \ln \left(y_{i 0}\right)\right\} \\
& +\theta^{*}\left\{P_{i s}(d) \ln \left(Y_{i s d 10}\right)+\left[1-P_{i s}(d)\right] \ln \left(Y_{i s g 10}\right)\right\} \\
& +\theta^{U}\left\{P_{i s}(d)\left[1-P_{i s}(\mathrm{job} \mid d)\right]+\left[1-P_{i s}(d)\right]\left[1-P_{i s}(\mathrm{job} \mid g)\right]\right\} \\
& \left.+P_{i s}(d) \Psi_{i}+\delta l_{i s}+\gamma_{s}+\mu_{i}^{\xi}+\varepsilon_{i s}\right),
\end{aligned}
$$

where $\theta^{*}=\theta \sum_{t=1}^{T} \beta^{t} \kappa_{t}$ and $\theta^{U}=\ln (r) \theta \sum_{t=1}^{T} \beta^{t}$. Likewise, the probability of dropping out from school $s$ given in equation (6) can now be written as

${ }^{20}$ Note that we do not explicitly model any of the choices during or after school (such as the choice to take particular courses in school, how many hours to work, or whether to pursue a postgraduate degree); however, these choices should be implicitly factored into the beliefs that are reported by the students.

${ }^{21}$ Here $\kappa_{t}=\prod_{l=1}^{t-1} g_{l} / \prod_{l=1}^{9} g_{l}$. Assuming that students reach age 30 in period $t=10$ is without loss of generality. 


$$
\begin{gathered}
P_{i s}(d)=F_{\xi}\left\{\theta\left[\ln \left(y_{i 0}\right)-\ln \left(y_{i 0}-F_{i s}\right)\right]-\left[\sum_{j=1}^{2} \alpha_{j} P_{i s}\left(a^{j}\right)+\alpha_{3} E_{i s}\left(a^{3}\right)\right]-\eta_{s}+\Psi_{i}\right. \\
\left.+\theta^{*}\left[\ln \left(Y_{i s d 10}\right)-\ln \left(Y_{i s g 10}\right)\right]+\theta^{U}\left[P_{i s}(\mathrm{job} \mid g)-P_{i s}(\mathrm{job} \mid d)\right]\right\} .
\end{gathered}
$$

Note that equations (7) and (8) implicitly assume that there is no uncertainty in $Y_{i s h 10}$ for $h=\{d, g\}$; that is, the student knows with certainty his earnings at age 30 if he enrolls in school $s$ and either drops out or graduates. We relax this assumption later in Section VI.C.3, using information on the subjective distribution of earnings that students report. We also assume the psychic cost is a linear function of the student's age and an indicator of whether parents' income is above the sample median, i.e., $\Psi_{i}=\lambda_{0}+\lambda_{1}\left(\right.$ age $\left._{i}\right)+\lambda_{2} I_{i}$ (above-median parental income). Moreover, since the schools considered are located in two different cities, we assume that $l_{s}$ is a dummy that equals 1 if school $s$ is in a city different from $i$ 's location at which he takes the survey, and zero otherwise.

Our goal is to estimate the parameter vector $\Theta=\left\{\left\{\alpha_{j}\right\}_{j=1}^{3}, \delta, \theta, \theta^{*}, \theta^{U}\right.$, $\left.\left\{\lambda_{j}\right\}_{j=0}^{2}, \eta_{s}, \gamma_{s}\right\}$, up to scale. In order to ensure strict preferences between choices, the $\varepsilon_{i s}$ 's and $\xi_{i s}^{j}$ 's are assumed to have a continuous distribution.

2. Identification and Estimation of the Preference Parameters

Under the assumption that the random terms $\left\{\varepsilon_{i s}\right\}$ are independent for every individual $i$ and choice $s$, and that they have a type I extreme value distribution, the difference $\varepsilon_{i s}-\varepsilon_{i n}(n \neq s)$ is distributed logistic (e.g., Train 2009). Conditional on the student's expectations for each school in his choice set $S_{i}$, the probability $\Pi_{i s}$ that student $i$ chooses school $s$ in the hypothetical constraint case is

$\Pi_{i s}=P\left(\tilde{U}_{i s}+\varepsilon_{i s}>\tilde{U}_{i n}+\varepsilon_{i n},(s, n) \in S_{i}, n \neq s\right)=\frac{\exp \left(\tilde{U}_{i s}\right)}{\sum_{n \in S_{i}} \exp \left(\tilde{U}_{i n}\right)}$,

where $\tilde{U}_{i s}$ is the expected utility maximized in equation (7), net of $\varepsilon_{i s}$.

Under the assumption that the error terms $\left\{\xi_{i s}^{g}\right\}$ and $\left\{\xi_{i s}^{d}\right\}$ have a type I extreme value distribution, $F_{\xi}$ is a logistic distribution and the subjective probability that a student drops out from school $s$ can be written as

$$
P_{i s}(d)=\frac{\exp \left(f_{i s}\right)}{1+\exp \left(f_{i s}\right)},
$$

where $P_{i s}(d)$ is the elicited subjective probability of dropout for respondent $i$ if he enrolls in school $s$, and $f_{i s}$ is the expression inside $F_{\xi}(\cdot)$ in equation (8). 
Each of the equations (9) and (10) can be estimated by maximum likelihood. Equation (9) is a multinomial logistic regression while equation (10) is a fractional logit like the one developed by Papke and Wooldridge (1996) for handling proportions data. However, since the same parameters appear in both, we estimate the equations jointly using the generalized method of moments (GMM), where the moments are the score vectors, that is, a vector of the first partial derivatives of the likelihood functions, one for each element of the parameter vector. The preference parameters of interest, $\theta$, are identified up to scale off of the variation in expectations across individuals and schools when we consider the constrained choice. ${ }^{22}$ As outlined in Section $\mathrm{V}$, there is substantial heterogeneity in the subjective data. ${ }^{23}$

In addition, madrassas and universities have different institutional features and it is possible that students have better information about the school type that they are currently enrolled in. We allow for this possibility by allowing for the variance for the random terms associated with the schools to differ depending on whether they are of a type different from the student's current school. We assume that VSU, SU, and IU belong to the "university" type, while the two madrassas belong to the "madrassa" type. Since discrete choice models are only identified up to the scale parameter (Train 2009), we normalize the variance of the random term for own school type to 1 and estimate the variance of the random terms for schools of the different type. In that case, equation (9) becomes

$$
\Pi_{i s}=\frac{\exp \left\{\tilde{U}_{i s} /\left[1+\omega_{1} D(s \neq i \text { 's current school type })\right]\right\}}{\sum_{n \in S_{i}} \exp \left\{\tilde{U}_{i n} /\left[1+\omega_{1} D(n \neq i \text { 's current school type })\right]\right\}},
$$

where $D(\cdot)$ equals 1 if school $s$ is of a type that is different from the student's current school. The parameter $\omega_{1}$ is estimated. We expect it to be greater than zero if students are more uncertain about outcomes for schools that are of a type different from their current school. We include a similar additional parameter, $\omega_{2}$, when estimating equation (10) to allow for differential uncertainty by school type in the decision to drop out as well.

${ }^{22}$ In the random utility models we use, since only differences in utility matter, only differences in the alternative-specific constants are relevant (Train 2009). Note further that $\mu_{i}^{\xi}$ does not depend on the school considered and is therefore not identified.

${ }^{23}$ Our survey was conducted with students currently enrolled in college. This implies that the preference parameters we estimate will only be representative of those currently enrolled. Also, our sample is not a random sample drawn from the universe of university students. Manski and Lerman (1977) show that with choice-based sampling, maximumlikelihood estimators are consistent under the logit functional form assumption and if the model includes a choice-specific constant (the inconsistency being confined to the estimates of these constants). The specification in (7) already includes choice-specific constants, $\gamma_{s}$. 
3. Revision of Subjective Expectations in Counterfactual Regimes

In addition to estimating the parameters of the utility function, we are interested in conducting various policy experiments. However, in these counterfactual regimes, beliefs about outcomes other than the ones the policies specifically target may also change. Relaxation of financial constraints, for example, by making schooling free-a policy we consider in Section VIImay make students more or less likely to drop out or may change the likelihood of parents approving of a school. Moreover, the goal of such policy experiments is to predict choices of individuals in counterfactual regimes at an age when they are first making the choice (i.e., school-leaving age in our context) and when no learning has occurred since enrollment (see discussion in Sec. VI.C.2). We describe below how we adjust beliefs for the counterfactual regimes.

Subjective probability of dropout.-We have modeled the subjective probability of dropout explicitly to be able to modify it according to the counterfactual regimes we consider such as reduction in school fees (see eq. [8]). Because the psychic cost of dropout is a function of age, we can also adjust the beliefs to school-leaving age.

Subjective probability of parental approval.-Parental approval for a given university depends on parental preferences over school's characteristics (including school fees) and labor market returns, and parental expectations of those. From the student's perspective, the subjective probability of parental approval depends on his perception of his parents' preferences and expectations, for which we do not have enough information. We estimate the underlying process of expectation formation by assuming that parental approval expectations vary systematically with the respondents' and schools' characteristics (including tuition fees and beliefs regarding ideology and labor market returns). We use student fixed effects since observable characteristics only explain a small part of the variation in beliefs. Student $i$ 's subjective parental approval for school $s$ is given by

$$
P_{i s}\left(a^{j}\right)=\frac{\exp \left(\kappa \mathbf{Z}_{i s}+\nu_{s}+\zeta_{i}\right)}{1+\exp \left(\kappa \mathbf{Z}_{i s}+\nu_{s}+\zeta_{i}\right)},
$$

where $v_{s}$ is a school fixed effect, $\zeta_{i}$ is an individual fixed effect, and $\mathbf{Z}_{i s}$ is a vector of individual- and school-specific characteristics. The vector $\mathbf{Z}_{i s}$ includes the school's ideology, graduation rank, expected earnings conditional on graduation and conditional on dropout, probability of employment conditional on graduation and conditional on dropout, school cost, interaction of the school cost with household income, distance, school type (a dummy for whether the school is a madrassa or not) interacted with the student's religiosity, and the school-type dummy interacted with religiosity and school cost. We estimate equation (12) as a fractional logit (similar 
to eq. [10]). We can then predict how subjective parental approval is revised in counterfactual regimes. ${ }^{24}$

Other beliefs. - We assume that the expectation formation process of the other beliefs (future earnings, subjective probability of employment, expected graduation rank, and school's ideology) does not depend on the parameters of the counterfactual regime we consider (such as school fees or access to credit markets).$^{25}$ When conducting the policy experiments, we however age-adjust all the beliefs. Let $b_{i q s}^{o}$ denote the belief of individual $i$, currently enrolled in school $q$, for outcome $o$ associated with school $s$. We estimate linear regressions of the form

$$
\begin{aligned}
b_{i q s}^{o}= & \theta_{0}+\zeta_{i q}+\eta_{s}+\theta_{1} \text { age }_{i}+\vartheta_{1}\left[\zeta_{i q} \times \operatorname{age}_{i}\right]+\vartheta_{2}\left[\zeta_{i q} \times \operatorname{age}_{i}^{2}\right] \\
& +\nu_{1}\left[\eta_{s} \times \text { age }_{i}\right]+\nu_{2}\left[\eta_{s} \times \text { age }_{i}^{2}\right]+\rho\left[\zeta_{i q} \times \eta_{s}\right] \\
& +\tau_{1}\left[\zeta_{i q} \times \eta_{s} \times \operatorname{age}_{i}\right]+\tau_{2}\left[\zeta_{i q} \times \eta_{s} \times \operatorname{age}_{i}^{2}\right]+\varepsilon_{i s},
\end{aligned}
$$

where $\zeta_{i q}$ is a fixed effect for $i$ 's current school $q, \eta_{s}$ is a fixed effect for the school the respondent is reporting his belief about, and $\operatorname{age}_{i}$ is the respondent's age. The specification uses a quadratic in age to adjust for learning, allowing for the effect to differ for students enrolled in different schools, and allowing it to vary for each of the choices. This regression is conducted separately for beliefs about employment likelihood (conditional on graduating and not graduating), earnings (conditional on graduating and not graduating), graduation rank, and consistency of school's teachings with one's own ideology. ${ }^{26}$

\section{B. Model Estimates}

Column 1 of table 6 presents the GMM estimates of the utility specification. Bootstrap standard errors are presented in parentheses. The model is estimated using the 1,866 respondents who have more than one school in their constrained choice set. ${ }^{27}$

${ }^{24}$ Because we use student fixed effects, we do not use age directly as a predictor. However, because we assume that they depend on other beliefs that are age adjusted (see below), the parental approval expectations are indirectly age adjusted as well.

${ }_{25}$ We do adjust these expectations when we consider policies that directly change them (e.g., earnings expectations when considering a policy providing information on population earnings). See Sec. VII.

${ }^{26}$ Our aim is to simply roll back the beliefs to age 17 (college-starting age) in the policy simulations, so the individual-specific residuals are retained. For example, take a respondent who is 20 years old. We obtain the age-adjusted belief by subtracting $(20-17) \hat{\theta}_{1}+$ $\hat{\vartheta}_{1}\left[\zeta_{i q}(20-17)\right]+\hat{\vartheta}_{2}\left[\zeta_{i q}\left(20^{2}-17^{2}\right)\right]+\hat{\nu}_{1}\left[\eta_{s}(20-17)\right]+\hat{\nu}_{2}\left[\eta_{s}\left(20^{2}-17^{2}\right)\right]+\hat{\tau}_{1}\left[\zeta_{i q} \eta_{s}(20-17)\right]+$ $\hat{\tau}_{2}\left[\zeta_{i q} \eta_{s}\left(20^{2}-17^{2}\right)\right]$ from the reported belief.

${ }_{27}$ Respondents who have only one school in their choice set have beliefs similar to those of respondents in the same school having more than one school in their choice set. 
TABLE 6

Generalized Method of Moments Estimates Based on Constrained Choice Set

\begin{tabular}{|c|c|c|}
\hline & $\begin{array}{l}\text { Baseline } \\
\text { Model } \\
(1)\end{array}$ & $\begin{array}{c}\text { Uncertainty } \\
\text { in Earnings } \\
\text { (2) }\end{array}$ \\
\hline Teachings aligned with ideology $\left(\alpha_{1}\right)$ & $\begin{array}{l}2.942 * * * \\
(.529)\end{array}$ & $\begin{array}{l}2.674 * * * \\
(.631)\end{array}$ \\
\hline Parents' approval of choice $\left(\alpha_{2}\right)$ & $\begin{array}{l}2.467 * * * \\
(.326)\end{array}$ & $\begin{array}{l}2.247 * * * \\
(.238)\end{array}$ \\
\hline Graduation rank $\left(\alpha_{3}\right)$ & $\begin{array}{l}.310^{*} \\
(.177)\end{array}$ & $\begin{array}{l}.058 \\
(.295)\end{array}$ \\
\hline Distance from current town ${ }^{\mathrm{a}}(\delta)$ & $\begin{array}{l}-.889 * * * \\
(.105)\end{array}$ & $\begin{array}{l}-.818 * * * \\
(.112)\end{array}$ \\
\hline $\ln ($ current period consumption) $(\theta)$ & $\begin{array}{l}.039 * * * \\
(.009)\end{array}$ & $\begin{array}{l}.046^{* * *} \\
(.007)\end{array}$ \\
\hline Age 30 expected $\ln ($ earnings $)\left(\theta^{*}\right)$ & $\begin{array}{l}.193^{* * *} \\
(.049)\end{array}$ & $\begin{array}{l}.221^{* *} \\
(.096)\end{array}$ \\
\hline Unemployment probabilities $\left(\theta^{U}\right)$ & $\begin{array}{c}-.934 * * \\
(.441)\end{array}$ & $\begin{array}{c}-.753 * \\
(.410)\end{array}$ \\
\hline$\gamma: \mathrm{VSU}$ & $\begin{array}{l}.246 \\
(.288)\end{array}$ & $\begin{array}{l}.400 \\
(.376)\end{array}$ \\
\hline$\gamma: \mathrm{SU}$ & $\begin{array}{c}-.584^{*} \\
(.333)\end{array}$ & $\begin{array}{l}-.313 \\
(.457)\end{array}$ \\
\hline$\gamma: \mathrm{IU}$ & $\begin{aligned}-.065 \\
(.396)\end{aligned}$ & $\begin{array}{l}.174 \\
(.566)\end{array}$ \\
\hline$\gamma:$ Madrassa-City 1 & $\begin{array}{l}.381 \\
(.276)\end{array}$ & $\begin{array}{l}.541 * * \\
(.240)\end{array}$ \\
\hline$\eta: \mathrm{VSU}$ & $\begin{array}{c}-.862 * * \\
(.398)\end{array}$ & $\begin{aligned}-.611 \\
(.466)\end{aligned}$ \\
\hline$\eta: \mathrm{SU}$ & $\begin{array}{l}-.593^{* *} \\
(.267)\end{array}$ & $\begin{aligned}-.535^{*} \\
(.304)\end{aligned}$ \\
\hline$\eta:$ IU & $\begin{array}{c}-.465^{* *} \\
(.199)\end{array}$ & $\begin{array}{l}-.436 * * \\
(.215)\end{array}$ \\
\hline$\eta$ : Madrassa-City 1 & $\begin{array}{c}-.334^{*} \\
(.188)\end{array}$ & $\begin{array}{l}-.419 * * * \\
(.146)\end{array}$ \\
\hline$\eta:$ Madrassa-City 2 & $\begin{array}{l}.000 \\
(.000)\end{array}$ & $\begin{array}{l}.000 \\
(.000)\end{array}$ \\
\hline Dropout psychological cost: Constant & $\begin{aligned}-1 & 1.378^{* * * *} \\
& (.527)\end{aligned}$ & $\begin{array}{c}-1.44 * * * \\
\quad(.491)\end{array}$ \\
\hline Dropout psychological cost: Age & $\begin{array}{l}.149 * * * \\
(.018)\end{array}$ & $\begin{array}{l}.128 * * * \\
(.017)\end{array}$ \\
\hline Dropout psychological cost: Above-median income & $\begin{array}{c}-.128 \\
(.230)\end{array}$ & $\begin{array}{l}.162 \\
(.232)\end{array}$ \\
\hline$\omega_{1}:$ School choice equation & $\begin{array}{l}.280 \\
(.256)\end{array}$ & $\begin{array}{l}.344 \\
(.273)\end{array}$ \\
\hline$\omega_{2}:$ Dropout equation & $\begin{array}{c}2.333 \\
(2.033)\end{array}$ & $\begin{array}{c}1.799 \\
(2.125)\end{array}$ \\
\hline $\begin{array}{l}\text { Number of students } \\
\text { Number of observations }\end{array}$ & $\begin{array}{l}1,866 \\
7,017\end{array}$ & $\begin{array}{l}1868 \\
7032\end{array}$ \\
\hline
\end{tabular}

Note.-Bootstrap standard errors in parentheses. See Sec. VI.A for model specification. Ideology and parents' approval are elicited on a $0-100$ scale, and normalized to $0-1$. Graduation rank is on a 1-100 scale, where 100 is the best rank (normalized to .01-1).

a Dummy that equals 1 if the school is in a town different from the respondent's current location.

* Significant at the 10 percent level.

** Significant at the 5 percent level.

*** Significant at the 1 percent level. 
The relative magnitudes of the first two estimates show the importance of the school-specific outcomes in school choice. The estimates for teaching aligned with ideology and parents' approval are positive, statistically different from zero at the 1 percent level, and of similar magnitude, suggesting that they are both equally important determinants of school choice. The coefficient on graduation rank is also positive, but 10 times smaller than the coefficient associated with teaching aligned with ideology. The negative and statistically significant estimate for school location, $\delta$, suggests that students have a distaste for schools located in a city different from their current location. The coefficients for current period consumption as well as age 30 expected log earnings are positive and significantly different from zero, suggesting that earnings are also a factor in school choice. The estimate of $\theta^{U}$ is negative, as one would expect for a replacement rate $r$ between 0 and 1 , and precisely estimated. Assuming $g=1.001$, the estimated $\theta, \theta^{*}$, and $\theta^{U}$ imply a discount factor of $\beta=0.85$ and a low replacement rate of 2.92 percent, consistent with the lack of unemployment benefits in Pakistan. ${ }^{28}$ Overall, this suggests that students take into consideration both pecuniary and nonpecuniary outcomes when deciding in which school to enroll.

Column 1 of table 6 also shows the estimates for the psychological cost entailed by dropping out. The positive coefficient associated with age suggests that older students experience less disutility from dropping out. Estimates of $\omega_{1}$ and $\omega_{2}$ - that is, the terms that allow for differential variance of the unobservable term for schools that are of a type different from a student's current school type-are positive but not significantly different from zero. This suggests that students are not more uncertain about outcomes for schools that are of a different type.

Table A4 presents the marginal effects of equation (12) using parental approval as the dependent variable. The sample is the same as the one used in table 6 , with an average of 3.8 observations per student. We see that a higher alignment of the teachings with own ideology, a higher/better graduation rank, higher expected earnings conditional on graduating, and a higher probability of employment (conditional on graduating and dropping out) all are associated with higher subjective parental approval. For example, increasing the alignment of the teaching with ideology by 10 percentage points increases parental approval by 3.9 percentage points. The negative estimate for school location indicates lower perceived parental approval for schools in a city different from the student's current location. Parental approval for "university type" schools is perceived to be lower for students with higher self-reported religiosity.

${ }^{28}$ The value for $g$ implies an average annual growth rate of 1 percent for a starting salary of Rs. 30,000 and a resulting salary (assuming a working lifespan of 40 years) of Rs. 45,194. This 50 percent increase in salary over the working lifetime is consistent with what is observed for males' real wages in the Pakistan Labour Force Survey for 2006-07 (Irfan 2008). 
1. Model Fit and "Out of Sample" Validation

Next, we assess the fit of the estimated model by comparing the modelpredicted choice to the stated choice in the data. Column 1 of table 7 shows the proportion of respondents in our sample who rank the school the highest in the constrained case. Columns 2 and 3 report statistics based on the predictions from our model. Column 2 reports the predicted choice, i.e., the proportion of students choosing a school, assuming a student chooses the school yielding the highest predicted probability. Column 3 reports the average predicted probabilities for each school, averaged over all respondents. As one would expect, the model fits the stated choices well, with only slight deviations. For example, 20.2 percent of the students state that IU is their preferred school, while the model-predicted choice (average probability) of choosing it is 22.2 percent (20.3 percent). Table A5 shows similarly good model fits for various subsamples. ${ }^{29}$

Using the fact that we asked students to report their school choice both with and without financial constraints, we next evaluate our model fit by conducting an exercise similar in spirit to an "out of sample" validation test. In particular, we use the estimates of the preference parameters from the GMM that rely on the constrained stated school choice and the probability of dropout (that is, estimates in col. 1 of table 6) and the estimates based on the parental approval equation (that is, estimates underlying the marginal effects in table A4) to predict students' subjective probabilities of dropout and parental approval for all schools when school costs are set to zero. We use these to then predict students' school choice when school costs are set to zero, and compare these predictions with no costs to students' unconstrained stated school choice. This validation test has an "out of sample" flavor; however, rather than comparing the predictions for a different sample, it does so for the same sample in a different state of the world (i.e., one without school costs).$^{30}$

Comparing column 4 of table 7 with column 5 , we see that the predicted choices match well students' unconstrained stated choices: for example, 37.4 percent (4.2 percent, 15.0 percent, and 20.0 percent) of the students state that they would enroll in VSU (SU, IU, and M-City 1) without school costs, while the model predicts a choice of enrollment of 29.1 percent (3.2 percent, 20.4 percent, and 20.3 percent, respectively). The weighted squared loss criterion to assess the fit of the model prediction (i.e., $\sum_{i=1}^{5} w_{i}\left(w_{i}-p_{i}\right)^{2}$, where $w_{i}$ is the enrollment in school $i$ derived from stated choice and $p_{i}$ is the model-based predicted enrollment) is also very

${ }^{29}$ Table A5 reports the predicted probabilities but results using the predicted choices are very similar.

${ }^{30}$ Our test relies on the assumption that students are able to correctly predict what they would do in the counterfactual state of no school costs. We believe this is a plausible assumption since the counterfactual scenario that students are asked to consider is a welldefined scenario that directly relates to their lives and to a decision they recently made. 
TABLE 7

MODEL FIT

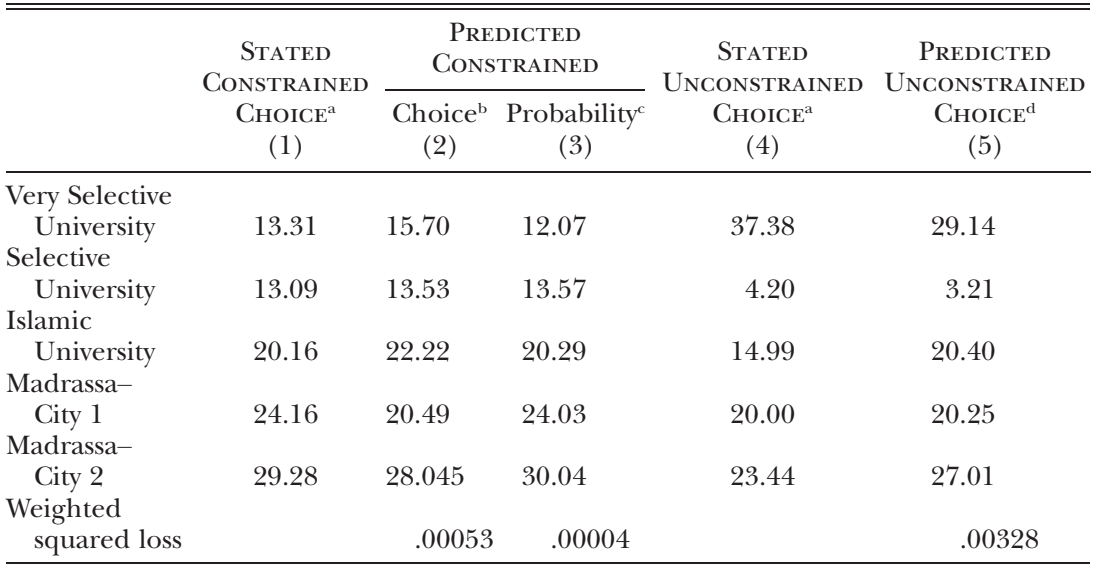

Note.-Proportions and probabilities are given as percentages.

a Proportion of students who rank the school the highest in the data.

b The model-predicted proportion of students choosing each school (assigning each student to the school with the highest predicted probability), in the constrained choice set case.

c The model-predicted probabilities of each school (averaged across respondents), in the constrained choice set case.

d The model-predicted proportion of students choosing each school, in the case where all schools are in the respondent's choice set.

low (0.003 for the predicted choices). Overall, we take this as strong evidence in favor of the model specification and data quality.

\section{Choice Elasticity}

We next investigate what our model estimates imply about the responsiveness of school choice to changes in self earnings. For each school, we increase beliefs regarding own earnings at age 30 (conditional on both graduating as well as dropout) by 1 percent. Based on the assumptions in our empirical model, any change in age 30 earnings will also impact life-cycle earnings. To assess how much more likely students would be to choose each school due to this increase in earnings, we compute choice elasticities (i.e., the percentage increase in the predicted probability of choosing a school given a 1 percent increase in future earnings at that school).

The mean elasticity (averaged across the five schools) is 0.117 and changes very little depending on the school choice. That is, while earnings matter, they play a small role in the choice. Our result of a relatively low response to changes in earnings is consistent with other studies of schooling choice (Arcidiacono 2004; Beffy et al. 2012; Wiswall and Zafar 2015). For example, Beffy et al. (2012), using data on French students, estimate 
earnings elasticities of between $0.09-0.12$ percentage points, depending on the major.

We also estimate the responsiveness of school choice to changes in unemployment risk. For each school, we increase the beliefs regarding being employed (conditional on graduating as well as dropout) by 1 percent. The mean elasticity is 0.34 ; that is, students are on average 0.34 percentage points more likely to choose a school if the employment prospects associated with that school increase by 1 percentage point. The estimate suggests that employment prospects are a relatively important factor in school choice.

\section{Willingness to Pay}

We can gain insight into the magnitude of the estimated parameters by translating the differences of utility levels into age 30 consumption $c$ that would make the student indifferent between giving up age 30 consumption and experiencing the outcome considered. Say, we are interested in determining the willingness to pay (WTP) to experience outcome $a_{j}$ with probability $P_{2}$ instead of probability $P_{1}$, other things being equal. Based on utility specification in equation (2), this implies the following indifference condition:

$$
\alpha_{j} P_{1}\left(a_{j}\right)+\theta^{*} \ln (c)=\alpha_{j} P_{2}\left(a_{j}\right)+\theta^{*} \ln (c+\mathrm{WTP}) .
$$

The WTP, as a percentage of age 30 consumption $c$, is then $\exp \left(\left\{\alpha_{j}\left[P_{1}\left(a_{j}\right)-P_{2}\left(a_{j}\right)\right]\right\} / \theta^{*}\right)-1$. So, for example, increasing the chance of gaining parents' approval by 2 percentage points, that is, $P_{2}=P_{1}+.02$, would yield a WTP of .226, based on the estimates in column 1 of table 6 . That is, students are on average willing to give up 22.6 percent of their age 30 consumption to increase the chance of gaining parents' approval of their school choice by 2 percentage points.

Column 1 of table 8 reports the willingness-to-pay estimates for the various outcomes. The first three cells are estimates of WTP to increase the three school-specific outcomes, $\left\{a_{j}\right\}_{j=1}^{3}$, by 2 percentage points. Students are willing to give up 26.3 percent ( 3.2 percent) in age 30 consumption to increase the chance of the school's teachings being consistent with their own ideology (graduation rank ) by 2 points. These estimates are very large and imply that students gain significant utility from each of these nonpecuniary outcomes, and that they are important drivers of school choice.

\section{Robustness Checks and Methodological Results}

This section reports a series of validation checks showing the robustness of our results. 
TABLE 8

Willingness to Pay, Based on Constrained Model Estimates

\begin{tabular}{|c|c|c|c|c|c|}
\hline & \multirow[b]{2}{*}{$\begin{array}{l}\text { BASELINE } \\
\text { MODEL } \\
(1)\end{array}$} & \multicolumn{2}{|c|}{$\begin{array}{c}\text { FIRST-YEAR } \\
\text { INTERACTION } \\
\text { MODEL }\end{array}$} & \multirow[b]{2}{*}{$\begin{array}{c}\text { UNCERTAINTY } \\
\text { IN EARNINGS } \\
(4)\end{array}$} & \multirow{2}{*}{$\begin{array}{c}\text { INDIRECT } \\
\text { MEASURES OF } \\
\text { ConSTRAINTS } \\
\text { (5) }\end{array}$} \\
\hline & & $\begin{array}{l}\text { First } \\
\text { Year } \\
(2)\end{array}$ & $\begin{array}{c}\text { Non-First } \\
\text { Year } \\
(3)\end{array}$ & & \\
\hline $\begin{array}{l}\text { Teachings aligned with } \\
\text { ideology }\end{array}$ & .263 & .268 & .225 & .215 & .319 \\
\hline Parents' approval of choice & .226 & .230 & .180 & .184 & .299 \\
\hline Graduation rank & .032 & .000 & .112 & .005 & .112 \\
\hline Distance from current town & -.097 & -.064 & -.096 & -.077 & -.149 \\
\hline Number of students & 1,866 & 671 & 1,173 & 1,868 & 2,069 \\
\hline
\end{tabular}

NoTE.- The table shows the proportion of age 30 earnings the respondent is willing to forgo for the following: a 2 percentage point increase in beliefs about teachings aligned with ideology, a 2 percentage point increase in beliefs about parents' approval of the choice, a .02 point increase (on a .01-1 scale) in expected graduation rank, and a .02 point increase (on a $0-1$ scale) in distance.

\section{Ex Post Rationalization}

Since our sampling strategy is choice based and students have been studying at their current school for a while, one concern may be that students' reported beliefs are biased, say due to cognitive dissonance or ex post rationalization (Festinger 1957). This would introduce systematic nonclassical measurement error in beliefs, which would bias the model estimates. The patterns in the data, however, indicate that this bias is unlikely to be large. For example, a nontrivial proportion ( 27 percent) of students rank a school different from their current school as their most preferred choice under their current credit constraints. Furthermore, this proportion is the same (25 percent) among students in later years (that is, those beyond the first year in their current institution), ${ }^{31}$ for whom ex post rationalization concerns are arguably stronger. We also see that 41 percent of students switch their most preferred school from the constrained to the unconstrained case (table 2); the corresponding proportion of students in later years who switch is again similar (39 percent). Students seem also aware of the different added values of the institutions, as reported by a similar relative ranking of self earnings beliefs across respondents enrolled in different schools (the various columns in table 4). Furthermore, previous research in the context of educational choices of US students has found little evidence of students tilting their beliefs about expected outcomes in favor of the options they had chosen (Zafar 2011a; Arcidiacono et al. 2012).

${ }^{31}$ Recall that we classify an M student as being first year if he is 20 years old or younger. Results are robust to other classifications. 
Yet, to address this, we exploit the variation in students' duration of enrollment in their school. If ex post rationalization of beliefs is a concern, it is likely to be more serious for the group of students who have been attending an institution for a longer period. We estimate the model in which we allow all the parameters to differ depending on whether the student is in the first year or not (that is, we include interactions of all parameters with a first-year dummy). We find little systematic difference in the parameter estimates by school year (except for the parameters associated with the psychic cost of dropout, which depend on age). Importantly, the WTP estimates for the two subsamples, reported in columns 2 and 3 of table 8 , are very similar. This suggests that our preference estimates are not biased due to this concern.

\section{Learning}

Another potential concern is that students may have had the opportunity to learn about the institution they are currently enrolled in (Stinebrickner and Stinebrickner 2014a). This learning would be problematic if we were using the elicited beliefs to make inference using the institution the students are currently attending as their choice. However, in our application, we ask students about their current school preferences, and estimate the choice model based on their current school preferences (not their currently enrolled institution) and current beliefs.

Still, we investigate whether there is evidence of learning. Figure A5 displays the distribution of responses for selective outcomes for the pooled sample by age. It shows that for some binary outcomes (such as parents approving of studying in Madrassa-City 1, or being employed conditional on graduating from IU), beliefs of younger respondents are relatively more likely to be in the middle of the response range (40-60, when elicited on a $0-100$ scale). On the other hand, beliefs about Very Selective University's teachings being consistent with own ideology or earnings expectations conditional on graduating from Very Selective University do not differ systematically with age. When estimating equation (13), we find that several of these age-interaction terms are significant. In fact, for four of the six regressions, we reject the hypothesis that the age-interaction terms are jointly different from zero. This is suggestive of beliefs evolving systematically with age. When conducting the policy experiments in Section VII, we apply these age adjustments.

\section{Uncertainty in Age 30 Earnings}

The empirical model assumes that the only uncertainty with regard to labor market earnings is about the likelihood of finding a job, conditional on graduating and dropping out. Conditional on being employed, students are assumed to know their earnings with certainty. We now relax this 
assumption. Our survey elicited students' subjective probability that their age 30 earnings conditional on working exceed two thresholds, for the case of both graduating from as well as dropping out of each of the schools (see app. A for the exact wording). We fit these two data points to an individualspecific beta distribution, and obtain the parameters of the two-parameter beta distribution. ${ }^{32}$

Columns 1-4 of table A6 present statistics (the mean, median, and standard deviation) of the average and the standard deviation of the fitted beta distributions for each school, conditional on graduating and dropping out. Two patterns are of note. First, the means of the expected earnings from the fitted distribution are very similar to the average point estimates presented in table 4 . Second, students exhibit substantial uncertainty about their future earnings, as reflected by the large standard deviations of the beta distributions.

For our estimation, the term $\ln \left(Y_{i s h}\right)$, where $h=\{g, d\}$ in equations (7) and (8), now becomes $E\left[\ln \left(Y_{i s h 10}\right)\right] .{ }^{33}$ Estimates based on the GMM estimation and using $E\left[\ln \left(Y_{i s h 10}\right)\right]$ based on the fitted distribution instead of the point estimates (that is, $\left.\ln \left(Y_{i s h 10}\right)\right)$ are presented in column 2 of table 6 . With the exception of the coefficient associated with graduation rank, which is smaller in magnitude and less precisely estimated, the estimates are very similar to those obtained in the baseline model, suggesting that not accounting for earnings uncertainty does not bias our model estimates. This is because, despite the uncertainty faced by respondents, $E\left[\ln \left(Y_{\text {ishlo }}\right)\right]$ based on the fitted distribution and $\ln \left(Y_{\text {ish } 10}\right)$ based on the point estimates tend to be very similar (as shown in cols. 5-8 of table A6). Column 4 of table 8 shows that the WTP estimates based on this model are very similar to those obtained from the baseline model (shown in col. 1).

\section{Advantage of Data on Direct Measures of Financial Constraints}

Absent direct measures on respondents' feasible choice set, researchers typically use proxies such as family background (for example, wealth and income) to capture financial constraints. To emphasize the advantage of

\footnotetext{
32 There are a total of 21,490 (2,149 respondents $\times 5$ school choices $\times$ igraduate, dropout\}) distributions to fit. We are unable to fit the data points in 4,071 (18.9 percent) of the cases; 987 cases are unfitted because the responses violate the monotonicity property of a cumulative distribution function, while in the remaining cases, the respondent assigns the same probability to the two thresholds. In these cases, we use the respondent's point estimate in the estimation (results are robust to dropping these observations). Overall, 18.1 percent of the students violate monotonicity at least once.

33 The beta distribution has a closed-form solution for this expectation, $E\left(\ln \left(Y_{\text {ish } 10}\right)\right)=[\psi(\alpha)-\psi(\alpha+\beta)](c-a)+a$, where $\psi$ is the digamma function, $[a, c]$ is the support of the distribution, and $\alpha$ and $\beta$ are the parameters of the beta distribution (obtained from fitting the data points). We set $a$ to zero and $c$ to Rs. 200,000 for nonmadrassa students and Rs. 100,000 for madrassa students (results are robust to other parameterizations).
} 
collecting data on direct measures, we reestimate the model under the scenario in which we did not have direct measures. For this purpose, we estimate our GMM model but we (1) assume that all the five schools are in the respondents' choice set, and (2) use parents' income as a proxy for constraints.

More specifically, this requires interacting the school-specific constant term, $\gamma_{s}$, in equations (1) and (2) with dummies for parents' income terciles. This introduces eight new terms (four school dummies interacted with the highest and middle income terciles, respectively) in the estimation. Binding credit constraints in this case would manifest themselves as students from the lower income terciles having a disutility for the more expensive school, relative to their higher income counterparts. This is exactly what we find: seven of the eight interaction terms have the correct (positive) sign and relative magnitudes.

Column 5 of table 8 shows that the WTP for the nonpecuniary factors implied by this model are somewhat larger than those from the baseline model. This is not entirely surprising: including schools with higher returns in the student's choice set that are otherwise not feasible and hence not chosen by the student would lead us to conclude a higher valuation for the nonpecuniary factors than the estimates based on direct measures of the feasible choice set. This suggests that using indirect measures of constraints may not substitute for eliciting direct measures of constraints, and may yield biased inference.

\section{Policy Experiments}

In this section, we use the estimated preference parameters to evaluate the implications of three types of policies: one that relaxes financial constraints, another that disseminates information about the objective returns to school types, and a final one that entails making the schools ideologically homogeneous. We investigate how these policies influence school enrollment and welfare of the students.

We are interested in determining the impact these policies would have on individuals when they are first making the decision of what college to attend (conditional on pursuing higher education). This is typically at the age of 17. Because of the possibility of learning as discussed in Section VI.C.2, we age-adjust all the beliefs in the policy simulations as if students were 17 years old. We first adjust beliefs about labor market outcomes, graduation rank, and ideology as outlined in equation (13). These adjusted beliefs are then used in the parents' approval equation (12). Since the psychic cost term in the dropout equation is a function of age, we also age-adjust the probability of dropout. Finally, we accordingly adjust the probability of dropout and parental approval for the policies we consider. These adjusted beliefs, in conjunction with the model parameters, 
are then used to determine the probability of the student choosing each school.

Our policy simulations should be viewed as providing evidence of the short-term responses, since in the long-term beliefs may evolve in ways not captured by our model. We also abstract away from general equilibrium considerations in these simulations; for example, if a large number of students switch to Western-style universities, the (subjective) labor market returns to such schools may change. We do not take such factors into account in the policy experiments; the simulations are only designed to illustrate the importance of each of the factors - financial constraints, information frictions, and nonpecuniary factors - in school choice. ${ }^{34}$

Column 1 of table 9 shows the average predicted probability of choosing each of the five schools in the constrained case when students are age 17 , which is our benchmark. In order to compute the possible welfare gains of instituting a policy, we compute the expected lifetime utility associated with the school chosen in the policy experiment $\left(s_{i}^{* p}=\right.$ $\arg \max _{s e S_{i}^{p}} E_{i}\left(\tilde{U}_{i s}\right)$, where $S_{i}^{p}$ is $i$ 's feasible choice set under policy $p$ ) and the school chosen in the constrained case $\left(s_{i}^{* c}=\arg \max _{s e S_{i}} E_{i}\left(\tilde{U}_{i s}\right)\right)$. In panel $\mathrm{B}$ of the table, for the various policies, we report the percent change in age 30 log earnings as well as the change in parents' approval and ideology that would generate a similar change in utility. ${ }^{35}$ We also show the proportion of respondents who experience a utility gain or loss as a result of the policy. Our simulations are made under the assumption that the only schools available are the ones we consider in the hypothetical choice scenarios.

\section{A. Relaxing Financial Constraints}

Columns 2-4 of table 9 report students' choices (in panel A) and welfare gains (in panel B) for three different policy experiments that relax credit constraints to varying extents.

Columns 2 and 3 are based on policies in which students have the option to borrow to finance their school costs at 3 percent and repay the loan over a 40 year period when they are working, the difference between the two being that in column 2, students can borrow for schooling-related expenses only after they have incurred the maximum education-related expenses that they reported they could cover. In column 3, they can borrow

\footnotetext{
${ }^{34}$ In the hypothetical scenarios, students are making their school decision alone but certainly take into consideration parental preferences since we find that parental approval matters importantly in their decision (Sec. II). Therefore, this aspect of intrahousehold decision making is captured to some extent in our framework.

${ }_{35}$ For the earnings equivalent, we show only the median. Given the low earnings elasticity and the sizable gains in utility from the various policies that we consider, the average earnings equivalent is extremely large in many cases.
} 
TABLE 9

Choices and Utility Changes for Different Policy Experiments

\begin{tabular}{|c|c|c|c|c|c|c|c|c|c|}
\hline & $\begin{array}{c}\text { Constrained } \\
\text { Case } \\
\text { (1) }\end{array}$ & $\begin{array}{c}\text { Partial } \\
\text { Financing } \\
\text { Available }^{\mathrm{a}} \\
\quad(2)\end{array}$ & $\begin{array}{c}\text { Full } \\
\text { Financing } \\
\text { Available }^{\mathrm{b}} \\
\text { (3) }\end{array}$ & $\begin{array}{c}\text { Free } \\
\text { Schooling } \\
\text { with Tax } \\
\text { (4) }\end{array}$ & $\begin{array}{c}\text { Admission } \\
\text { Requirement }^{\mathrm{d}} \\
(5)\end{array}$ & $\begin{array}{c}\text { Admission } \\
\text { Requirement }+ \\
\text { Full Financing } \\
(6)\end{array}$ & $\begin{array}{l}\text { Information } \\
\text { (7) }\end{array}$ & $\begin{array}{l}\text { Information }+ \\
\text { Full Financing } \\
\text { (8) }\end{array}$ & $\begin{array}{c}\mathrm{IU} \\
\text { Ideology }^{\mathrm{e}} \\
(9)\end{array}$ \\
\hline & \multicolumn{9}{|c|}{ A. Mean Probability (\%) of Choosing Each School ${ }^{\mathrm{f}}$} \\
\hline Very Selective University & 14.24 & 27.88 & 28.98 & 29.04 & 13.2 & 24.4 & 14.55 & 29.33 & 14.03 \\
\hline Selective University & 15.43 & 10.4 & 9.43 & 9.49 & 17.57 & 12.95 & 15.61 & 9.66 & 15.07 \\
\hline Islamic University & 18.09 & 20.43 & 19.88 & 19.81 & 18.19 & 19.98 & 18.12 & 19.95 & 14.14 \\
\hline Madrassa-City 1 & 24.48 & 18.27 & 19.52 & 19.49 & 24.06 & 20.15 & 24.41 & 19.35 & 27.53 \\
\hline \multirow[t]{2}{*}{ Madrassa-City 2} & 27.77 & 23.02 & 22.19 & 22.18 & 26.97 & 22.52 & 27.31 & 21.71 & 29.24 \\
\hline & \multicolumn{9}{|c|}{ B. Utility Changes ${ }^{g}$} \\
\hline $\begin{array}{l}\text { Median earnings } \\
\text { equivalent }{ }^{\mathrm{h}}(\%)\end{array}$ & & 0 & 9.77 & 9.55 & 0 & 4.1 & 0 & 9.32 & 0 \\
\hline $\begin{array}{l}\text { Parents' approval } \\
\text { equivalent } \mathrm{t}^{\mathrm{i}} \\
\text { (percentage points) }\end{array}$ & & $\begin{array}{l}9.10 \\
{[0]}\end{array}$ & $\begin{array}{r}13.08 \\
{[.73]}\end{array}$ & $\begin{array}{l}3.74 \\
{[.72]}\end{array}$ & $\begin{array}{l}-2.07 \\
{[0]}\end{array}$ & $\begin{array}{r}10.83 \\
{[.31]}\end{array}$ & $\begin{array}{l}.1 \\
{[0]}\end{array}$ & $\begin{array}{l}12.76 \\
{[.70]}\end{array}$ & $\begin{array}{c}-12.1 \\
{[0]}\end{array}$ \\
\hline $\begin{array}{l}\text { Ideology equivalent } \\
\text { (percentage points) }\end{array}$ & & $\begin{array}{l}7.64 \\
{[0]}\end{array}$ & $\begin{array}{r}10.97 \\
{[.61]}\end{array}$ & $\begin{array}{l}3.14 \\
{[.6]}\end{array}$ & $\begin{array}{l}-1.73 \\
{[0]}\end{array}$ & $\begin{array}{l}9.08 \\
{[.26]}\end{array}$ & $\begin{array}{l}.09 \\
{[0]}\end{array}$ & $\begin{array}{l}10.7 \\
{[.59]}\end{array}$ & $\begin{array}{c}-10.15 \\
{[0]}\end{array}$ \\
\hline
\end{tabular}




\begin{tabular}{|c|c|c|c|c|c|c|c|c|}
\hline $\begin{array}{l}\text { Proportion with } \\
\text { utility loss }\end{array}$ & 0 & 0 & 44.03 & 3.95 & 0 & 0 & 0 & 33.76 \\
\hline Proportion with & & & & & & & & \\
\hline utility gain & 18.42 & 60.52 & 55.97 & 0 & 57.07 & 1.62 & 62.53 & 22.75 \\
\hline Proportion switch ${ }^{\mathrm{k}}$ & 18.42 & 18.98 & 22.95 & 3.95 & 15.12 & 1.62 & 19.15 & 10.52 \\
\hline $\begin{array}{c}\text { Mean annual loan/ } \\
\text { subsidy (rupees) }\end{array}$ & 38,510 & 106,953 & 205,590 & & 87,898 & & 107,025 & \\
\hline
\end{tabular}

a Regime in which students can borrow at 3 percent to finance additional school costs (on top of the self-reported maximum that they can afford), with repayment over 40 years.

begime in which students can borrow at 3 percent to finance all school costs, with repayment over 40 years.

c Regime in which schooling is free, financed out of a tax on later labor market earnings.

d Regime with an admission requirement, in which a student is "admitted" only if expected graduation rank is in the top half.

e Regime in which the ideology of each school is made homogeneous (and is set to the IU ideology).

f The model-based predicted probability of choosing each school (averaged across respondent).

$\wedge \quad{ }^{g}$ Statistics in this panel are computed by assigning the student to the school with the highest predicted probability in that regime.

$\infty \quad \mathrm{h}$ The median age 30 earnings change equivalent that would result in the change in utility, as a result of the change in school choice relative to the baseline case.

i The equivalent change in parents' approval (on a 0-100 scale) that would result in the change in utility, as a result of the change in school choice relative to the baseline case. Mean [median] reported.

j Proportion of students who experience a utility loss under the counterfactual policy, relative to the baseline.

${ }^{k}$ Proportion of students who switch to a different school under the counterfactual policy, relative to the baseline. 
for all schooling-related expenses regardless of their financial circumstances. Relative to the policy in column 2, this policy also allows students to smooth consumption (between the in-college and post-college periods). Column 4 reports estimates based on a free-schooling policy funded by income tax paid by the students over a 40 year period when they are working and earn more than Rs. 40,000 per year. ${ }^{36}$ Notice that credit constraints are entirely eliminated in all three policies, and hence $S_{i}^{p}$ includes all five schools.

A policy that provides student loans to partially finance schooling (col. 2) yields substantially different enrollment: enrollment at VSU almost doubles, while enrollment at SU falls. Enrollment at IU rises slightly, and falls by more than 10 percentage points at the two madrassas combined. Panel B of table 9 shows that 18.4 percent of the respondents take out a student loan and, as a result, experience gains in utility by now attending a school that earlier was not in their constrained choice set. This policy, relative to the baseline constrained case, leads to tremendous gains in utility for the average respondent. The average ideology equivalent change is a 7.6 point increase; given the WTP estimates in table 8 , this is a large gain in welfare. The last row of the table shows that the average loan students take out in this case is Rs. 38,510 annually, an amount very close to the average parents' monthly income of IU students (table 1). The full-financing policy (col. 3), as expected, results in slightly more switching and larger welfare gains than the policy in column 2. In fact, more than 60 percent of the students now experience gains in welfare, some of it being due to the ability to smooth consumption. The median earnings equivalent change is also sizable (an increase of 9.8 percent).

Note that there may be psychological aversion to taking out a loan (Stinebrickner and Stinebrickner 2008; Field 2009), especially in this context, where charging interest is forbidden by Islamic law. We therefore consider a policy that is instead relabeled as a tax on later lifetime labor earnings of students. Column 4 of table 9 shows the impact of such a policy that provides free schooling paid out of a tax on earnings. This policy yields enrollment changes similar to those in the student loans case (col. 3), with 23 percent of the students choosing a school different from the constrained case. About 56 percent of the students experience gains in utility, and 44 percent are now worse off because of higher taxes on labor market earnings. The annual subsidy amount, as expected, is much higher: almost twice the size of the full-financing policy.

These policies are conducted under the assumption that all students can gain admissions to all schools. However, ignoring admission constraints

${ }^{36}$ This is similar in spirit to the income-based repayment scheme in the United States and public student loan repayment in the United Kingdom, for which students make repayment only if their income is above a given threshold. Results are qualitatively similar to other choices of the threshold at which taxes are imposed. 
may overstate the role of financial constraints. In the absence of data on objective measures of student ability, we use the student's reported schoolspecific expected graduation rank as a proxy for admission eligibility. As long as students' beliefs about graduation rank have some power in predicting their actual rank, this exercise is informative. Aschool is now assumed to be in the student's choice set if he believes he will rank in the top half of the graduating class. Column 5 shows the enrollment distribution under this policy (that is, a regime with admission and financial constraints). As expected, relative to the baseline, enrollment in the most selective school (VSU) is now somewhat lower. Column 6 shows the impact of the availability of full financing (i.e., the policy in col. 3) combined with this admissioneligibility requirement. The enrollment shift is only slightly lower than in the corresponding case with no admission requirements (col. 3). Likewise the welfare gains are only slightly lower than those in column 4 . For example, the average parental approval equivalent change is a 10.8 point increase, versus a 13.1 point increase in the case with no admission restrictions. This suggests that ignoring admission requirements does not bias our conclusions much.

\section{B. Providing Earnings Information}

Given a large literature that shows that students may be misinformed about the returns to schooling and that providing objective information about returns may impact choices (Jensen 2010; Wiswall and Zafar 2015), we next investigate whether such information dissemination has an impact in our context. If students' self earnings beliefs are based, in part, on their perceived population beliefs, and their population beliefs are inaccurate, then such an intervention can have large effects. We implement this policy as follows: we assume that the median student's population earnings beliefs $Y_{\mathrm{pop}, s h 10}^{\text {median }}$ (that is, beliefs about age 30 earnings of an average graduate or dropout of each of the various schools, reported in table 3) is an unbiased estimator of the true average population earnings. Given the statistics in table 3 , and how similar those medians are to the average earnings reported by the school administrators (col. 6), this is a reasonable assumption. We then purge each student's self beliefs of the forecast error in their self population beliefs, such that $Y_{i s h 10}^{*}=Y_{\text {ish } h 0}\left(Y_{\text {pop, }, s h 10}^{\text {median }} / Y_{\text {pop, }, i s h 10}\right), h=\{d, g\} .{ }^{37}$ The quantity $Y_{i s h 10}^{*}(h=\{d, g\})$ is then individual $i$ s beliefs about own age 30 earnings if he had information about the true population earnings. We use these purged earnings beliefs to update the subjective probabilities of parental approval and probabilities of dropout accordingly, and determine the school that yields the highest expected utility for the individual.

\footnotetext{
37 We skip the derivation steps here. Interested readers are instead referred to Arcidiacono et al. (2012), who implement a similar policy experiment.
} 
Column 7 of table 9 reports the results based on this policy experiment. We see that the proportion of students choosing each of the schools is similar to that in column 1 . The limited change in enrollment may be the result of the inability of students to move due to financial constraints. We therefore combine, in column 8 , a policy in which students are provided with both the availability of full financing (as in the policy in col. 3) and information about returns to schooling. However, we see that both the school enrollment and welfare gains are quite similar to those under the full-financing policy shown in column 3. Overall, this suggests that providing information on earnings in this sample of students - a selective group motivated enough to pursue the equivalent of a bachelor's degree-does not have a large impact on students' school choices in this context. ${ }^{38}$

\section{Homogenizing Schools' Ideology}

Finally, we investigate the impact of another experiment that makes the schools more homogeneous in terms of their ideological blend. For this simulation, we make the ideology of all schools equal to that of Islamic University (that is, we replace each student's beliefs about the school's teachings being consistent with their own ideology with the student's beliefs of the ideology of Islamic University being consistent with their own, and update the subjective probabilities of parental approval and probabilities of dropout accordingly).

In column 9, we see limited impact of this experiment on students' enrollment (which continues to be similar to that in the constrained case). However, a third of the students would now be worse off relative to the baseline. This underscores the large role of nonpecuniary factors and the heterogeneity in demand for ideology.

\section{Conclusion}

The choice of a higher education institution plays a major role in determining the employability and earnings of university students, both in the developed and in the developing world. This paper investigates the role of expected monetary returns, nonpecuniary factors enjoyed at school, and financial constraints in the choice of higher education institutions, in the context of urban Pakistan. This context is relevant because the higher education system in Pakistan is similar to the rest of South Asia, a region

\footnotetext{
38 These results may at first be surprising, given that students have substantial heterogeneity in beliefs. However, there are two main factors driving them. First, as seen in Sec. II, choice elasticities with respect to earnings are quite small. Second, most students accurately perceive the relative ranking of schools in terms of earnings. Since, to a large extent, relative earnings are important for school choice, the additional information provided by the policy has little impact on final outcomes.
} 
where a quarter of the world population lives and also one that is disproportionately young. As South Asian countries develop their industry and service sectors, the role of higher education in training a skilled workforce is becoming critical. In this environment, we find financial constraints to be important in determining students' university choice, conditional on going to university. In particular, lifting those constraints would double enrollment at the most expensive elite university and increase lifetime utility substantially. Nonmonetary outcomes enjoyed at school play a very large role in students' higher education choice. For example, students are willing to give up more than a quarter of age 30 consumption to increase the chance of the school's teachings being consistent with their own ideology by 2 percentage points. While future earnings matter, their role in determining university choice is only marginal.

Our results have important policy implications for the design of programs aiming at improving students' human capital and their future labor market prospects in South Asia. Relatively inexpensive policies such as student loans or subsidies paid out of taxes (by the students) would have large positive impacts on students' welfare. A full-financing policy in our context leads to welfare gains for more than 60 percent of the sample. We also find that providing information on earnings would have a limited impact on enrollment and welfare. Our results, however, should not be interpreted as implying that there are generally few gains from information campaigns in a setting with low higher educational enrollment. Instead such information campaigns should be targeted to populations in which misinformation is likely to be more prevalent, or be about nonpecuniary outcomes. Finally, we document large and heterogeneous demand for school-specific ideology; making schools more homogeneous along this dimension would lead to substantial welfare losses.

There are several avenues for future research. First, our sample is restricted to university students, and so we cannot conclude how participation in higher education would change based on the policies we consider. Given the large impact of relaxing financial constraints in our sample, availability of student loans or university tuition subsidies may also have an impact on the extensive margin and increase overall participation in higher education; we therefore speculate that the welfare gains are likely to extend beyond university students. Second, our hypothetical scenarios treat the student as the sole decision maker. In reality, such decisions are likely to be made jointly in consultation with other people (for example, parents and extended family members). Future work that sheds light on this would be immensely valuable.

Finally, in today's world, students are being confronted with radically expanding higher education choices due to, for example, the growth of for-profit universities in the United States and the emergence of a private and religious sector in higher education in many developing countries. 
Our approach - of combining rich data on subjective expectations, feasible choice set, and stated school choices in hypothetical scenarios-illustrates the potential of using "direct" elicitation methods to identify financially constrained individuals and to make inference on preferences for both pecuniary and nonpecuniary factors to better understand the determinants of human capital choices. In addition, given the dominance of nonpecuniary and psychic factors in explaining education choices and the inability of the literature to unpack them (Eisenhauer et al. 2015), our approach is particularly promising.

\section{Appendix A}

\section{A. Data Collection}

Data collection was conducted by the Survey Center affiliated with Islamic University. To signal credibility of the study, members of the staff of the institution at which data were being collected were also hired for the data collection. The survey sessions were conducted in groups of 50-100 students in a classroom at the students' institution. The rooms were large enough to ensure respondent anonymity. An anonymous questionnaire was given to each participant, read out by a member of the survey team, and projected on a computer projector. The survey instrument was administered in Urdu at all institutions except VSU, where it was conducted in English, since students there are more used to reading and writing in English. The survey took about 90 minutes to complete. Students were compensated Rs. 200 (USD 2.5) for completing the survey, and were additionally compensated for some experiments embedded in the survey (average compensation for which was Rs. 600). The total average compensation of Rs. 800 (USD 10) was substantial in the context of our setting. ${ }^{39}$ Delavande and Zafar (2015) use data from the same survey.

\section{B. Selected Survey Questions}

We present below the wording for several relevant expectations questions.

Choice set.-Students were asked about the maximum education-related expenses that they and their family can cover: "What is the maximum of the monthly expenses (including tuition, room, and board) that you and your family would be able to pay for you to be enrolled in school without any external financial aid?"

In addition, for each of the five institutions, students were asked about perceived net costs: "What do you think are the monthly expenses (including tuition, room, and board) that you would incur on average (net of any financial help such as scholarships, loans, and grants that you could secure) if you were enrolled in the institutions listed below?"

39 The 2009 per capita GNI at purchasing power parity in Pakistan was $\$ 2,710$, compared to $\$ 46,730$ in the United States. This means the average compensation of USD 10 corresponds to 0.4 percent of the GNI per capita. The US equivalent would be approximately USD 170 . 
Schools for which the perceived net costs did not exceed the maximum expenses that the student reports that he (and his family) can pay are then defined as being in the student's constrained choice set.

Expectations about population earnings.- - Consider a typical male student who graduates from each of the institutions below and who is working at age 30 . Think about the kinds of jobs that will be available to him. How much do you think he could earn per month on average at the age of 30 at these jobs?"

Expectations about own future earnings conditional on graduation.- "Consider the hypothetical situation where you graduate from each of the institutions listed below. Look ahead to when you will be 30 years old and suppose that you are working then. Think about the kinds of jobs that will be available to you. How much do you think you could earn per month on average at the age of 30 at these jobs?"

Expectations about own future earnings conditional on dropping out.- "Consider the hypothetical situation where you are enrolled in each of the institutions listed below, and you drop out of that institution without completing the degree. Look ahead to when you will be 30 years old and suppose that you are working then. Think about the kinds of jobs that will be available to you. How much do you think you could earn per month on average at the age of 30 at these jobs?"

Uncertainty in own future earnings. - "Consider the hypothetical situation where you graduate [drop out] from each of the institutions listed below. In the previous question, we asked you to think about your average monthly earnings at age 30 if you were working and if you were to graduate [drop out] from each of the institutions. However, for some people, it may be hard to predict how much they would earn at age 30 . In this question, we ask you to think about the percent chance (or chances out 100) that your earnings at age 30 will be above certain thresholds if you are working. What do you think is the percent chance that your monthly earnings at age 30 will be above Rs. L1, if you graduated [dropped out] from institution $\mathrm{X}$ ? And, what do you think is the percent chance that your monthly earnings at age 30 will be above Rs. L2, if you graduated [dropped out] from institution X?"

L1 and L2 were the same for each of the school choices, but for meaningful variation in responses across and within individuals, they varied across the schools that the survey was conducted in. For M students, L1 and L2 were set to Rs. 15,000 and Rs. 30,000, respectively. For VSU students, they were set to Rs. 25,000 and Rs. 75,000, respectively. For SU and IU students, they were set to Rs. 20,000 and Rs. 50,000.

Probability of employment conditional on graduation.- - Consider the hypothetical situation where you graduate from each of the institutions listed below. Look ahead to when you will be 30 years old. What do you think is the percent chance (or chances out of 100) that you would have a job at the age of 30?"

Beliefs about ideology.- - Consider the situation where you decided to enroll as a student in each of the institutions listed below. What do you think is the percent chance (or chances out of 100) that the materials you were taught at each of these institutions would be consistent with your own ideology and thinking?"

Beliefs about parents' approval.- - "Consider the situation where you decided to enroll as a student in the institutions listed below. What do you think is the percent chance (or chances out of 100) that your parents would approve of you studying at each of them?" 
Beliefs about graduation rank.- "Consider the situation where you decided to enroll as a student in the institutions listed below. What do you think your rank would be out of 100 students at each of the institutions when you graduated? (A rank of 1 would mean that you were the top student at the institution, while 100 would mean that you were ranked last at that institution.)"

\section{References}

Abbott, B., M. Costas, G. Violante, and G. Gallipoli. 2016. "Education Policy and Intergenerational Transfers in Equilibrium." Cowles Found. Discussion Paper no. 1887R. Available at SSRN: https://ssrn.com/abstract $=2750100$.

Adamowicz, W., J. Louviere, and M. Williams. 1994. "Combining Stated and Revealed Preference Methods for Valuing Environmental Amenities." J. Environmental Econ. and Management 26:271-92.

Ahmad, M. 2004. "Madrassa Education in Pakistan and Bangladesh." In Religious Radicalism and Security in South Asia, edited by S. Limaye, M. Malik, and R. Wirsing. Honolulu, HI: Asia-Pacific Center for Security Studies.

Ameriks, John, Joseph S. Briggs, Andrew Caplin, Matthew D. Shapiro, and Christopher Tonetti. 2015. "Long-Term-Care Utility and Late-in-Life Saving." Working Paper no. 20973 (February), NBER, Cambridge, MA.

Arcidiacono, P. 2004. "Ability Sorting and the Returns to College Major." J. Econometrics 121 (1-2): 343-75.

Arcidiacono, P., J. Hotz, and S. Kang. 2012. "Modeling College Major Choices using Elicited Measures of Expectations and Counterfactuals." J. Econometrics 166:3-16.

Asadullah, M. 2009. "Returns to Private and Public Education in Bangladesh and Pakistan: A Comparative Analysis." J. Asian Econ. 20 (1): 77-86.

Attanasio, O., and K. Kaufmann. 2014. "Education Choices and Returns to Schooling: Intrahousehold Decision Making, Gender and Subjective Expectations." J. Development Econ. 109C:203-16.

Barack, L. 2014. "Higher Education in the 21st Century: Meeting Real-World Demands." Research report, Economist Intelligence Unit.

Beffy, M., D. Fougere, and A. Maurel. 2012. "Choosing the Field of Study in PostSecondary Education: Do Expected Earnings Matter?” Rev. Econ. and Statis. 94 (1): 334-47.

Belley, P., and L. Lochner. 2007. "The Changing Role of Family Income and Ability in Determining Educational Achievement." J. Human Capital 1:37-89.

Ben-Akiva, M. E., and Morikawa, T. 1990. "Estimation of Switching Models from Revealed Preferences and Stated Intentions." Transportation Res. 24A (6): 485-95.

Berger, M. 1988. "Predicted Future Earnings and Choice of College Major." Indus. and Labor Relations Rev. 41 (3): 418-29.

Berman, E., and A. Stepanyan. 2004. "How Many Radical Islamists? Indirect Evidence from Five Countries." Working paper, Dept. Econ., Univ. California, San Diego.

Betts, J. 1996. "What Do Students Know about Wages? Evidence from a Survey of Undergraduates." J. Human Resources 31 (1): 27-56.

Bozzoli, C., B. Tilman, and T. Muhumuza. 2011. "Does War Influence Individual Expectations?" Econ. Letters 113 (3): 288-91.

Buchinsky, M., and P. Leslie. 2010. "Educational Attainment and the Changing U.S. Wage Structure: Dynamic Implications on Young Individuals' Choices." J. Labor Econ. 28 (3): 541-94. 
Cameron, S., and J. Heckman. 1998. "Life Cycle Schooling and Dynamic Selection Bias: Models and Evidence for Five Cohorts of American Males." J.P.E. 106:262-333.

Cameron, S., and C. Taber. 2004. "Estimation of Educational Borrowing Constraints Using Returns to Schooling." J.P.E. 112 (1): 132-82.

Card, D. 1999. "The Causal Effect of Education on Earnings." In Handbook of Labor Economics, vol. 3, edited by O. C. Ashenfelter and D. Card, 1801-63. Amsterdam: Elsevier.

Carneiro, P., and J. Heckman. 2002. "The Evidence on Credit Constraints in PostSecondary Schooling." Econ. J. 112:705-34.

Cunha, F., and J. Heckman. 2007. "Identifying and Estimating the Distribution of Ex Ante and Ex Post Returns to Schooling: A Survey of Recent Developments." Labour Econ. 14 (6): 870-93.

Cunha, F., J. Heckman, and S. Navarro. 2005. "Separating Uncertainty from Heterogeneity in Life Cycle Earnings." Oxford Econ. Papers 57 (2): 191-261.

Delavande, A. 2008. "Pill, Patch or Shot? Subjective Expectations and Birth Control Choice." Internat. Econ. Rev. 49 (3): 999-1042.

2014. "Probabilistic Expectations in Developing Countries." Ann. Rev. Econ. 6:1-20.

Delavande, A., and H.-P. Kohler. 2009. "Subjective Expectations in the Context of HIV/AIDS in Malawi." Demographic Res. 20: 817-74.

Delavande, A., and C. Manski. 2010. "Probabilistic Polling and Voting in the 2008 Presidential Election: Evidence from the American Life Panel." Public Opinion Q. 74 (3): 433-59.

Delavande, A., and B. Zafar. 2015. "Stereotypes and Madrassas: Experimental Evidence from Pakistan." J. Econ. Behavior and Org. 118:247-67.

D'Haultfoeuille, X., and A. Maurel. 2013. "Inference on Inference on an Extended Roy Model, with an Application to Schooling Decisions in France." J. Econometrics 174:95-106.

Eisenhauer, P., J. Heckman, and S. Mosso. 2015. "Estimation of Dynamic Discrete Choice Models by Maximum Likelihood and the Simulated Method of Moments." Internat. Econ. Rev. 56 (2): 331-57.

Festinger, L. 1957. A Theory of Cognitive Dissonance. Stanford, CA: Stanford Univ. Press.

Field, E. 2009. "Educational Debt Burden and Career Choice: Evidence from a Financial Aid Experiment at NYU Law School." American Econ. J.: Appl. Econ. 1:1-21.

Flyer, F. 1997. "The Influence of Higher Moments of Earnings Distributions on Career Decisions." J. Labor Econ. 15 (4): 689-713.

Galiani, S., A. Murphy, and J. Pantano. 2015. "Estimating Neighborhood Choice Models: Lessons from a Housing Assistance Experiment.” A.E.R. 105 (11): $3385-415$.

Gigerenzer, G. 1991. "How to Make Cognitive Illusions Disappear: Beyond Heuristics and Biases." European Rev. Social Psychology 2:83-115.

Giuliano, P., and A. Spilimbergo. 2014. "Growing Up in a Recession." Rev. Econ. Studies 81 (2): 787-817.

Giustinelli, P. 2016. "Group Decision Making with Uncertain Outcomes: Unpacking Child-Parent Choice of the High School Track." Internat. Econ. Rev. 57 (2): 573-602.

Gurgand, M., A. Lorenceau, and T. Mélonio. 2011. "Student Loans: Liquidity Constraint and Higher Education in South Africa." Agence Française de Développement Working Paper no. 117. Available at SSRN: https://ssrn.com /abstract $=1969424$. 
Hensher, D. A., and M. Bradley. 1993. "Using Stated Response Choice Data to Enrich Revealed Preference Discrete Choice Models.” Marketing Letters 4 (2): 139-51.

Higher Education Commission Pakistan. 2012. "Annual Report 2010-11.” https:/ / www.hec.gov.pk/english/news/HECPublications/Annual Report 2010-11.pdf.

Irfan, M. 2008. "Pakistan's Wage Structure During 1990/91-2006/07." Working paper, Pakistan Institute of Development Economics.

Jacob, B., and L. Lefgren. 2007. "What Do Parents Value in Education? An Empirical Investigation of Parents' Revealed Preferences for Teachers." Q.J.E. 122 (4): 1603-37.

Jacob, B., B. McCall, and K. Stange. 2018. "College as Country Club: Do Colleges Cater to Students' Preferences for Consumption?” J. Labor Econ. 36 (2): 30948.

Jaffry, S., Y. Ghulam, and V. Shah. 2007. "Returns to Education in Pakistan." Pakistan Development Rev. 46 (4): 833-52.

Jensen, R. 2010. "The Perceived Returns to Education and the Demand for Schooling." Q.J.E. 125 (2): 515-48.

Kaufmann, K. 2014. "Understanding the Income Gradient in College Attendance in Mexico: The Role of Heterogeneity in Expected Returns." Quantitative Econ. 5 (3): 583-630.

Keane, M., and K. Wolpin. 2001. "The Effect of Parental Transfers and Borrowing Constraints on Educational Attainment." Internat. Econ. Rev. 42:1051-103.

Lang K. 1993. "Ability Bias, Discount Rate Bias, and the Return to Education." Working paper, Dept. Econ., Boston Univ.

Lochner, L. 2007. "Individual Perceptions of the Criminal Justice System." A.E.R. 97:444-60.

Lochner, L., and A. Monge-Naranjo. 2012. "Credit Constraints in Education." Ann. Rev. Econ. 4:225-56.

Louviere, J., D. Hensher, and J. Swait. 2000. Stated Choice Methods: Analysis and Applications. Cambridge: Cambridge Univ. Press.

Lovenheim, Michael. 2011. "The Effect of Liquid Housing Wealth on College Enrollment." J. Labor Econ. 29 (4): 741-71.

Malmedier, U., and S. Nagel. 2016. "Learning from Inflation Experiences." Q.J.E. 131 (1): 53-87.

Manski, C. 1993. "Adolescent Econometricians: How Do Youth Infer the Returns to Schooling?" In Studies of Supply and Demand in Higher Education, edited by Charles Clotfelter and Michael Rothschild, 43-57. Chicago: Univ. Chicago Press.

. 2004. "Measuring Expectations." Econometrica 72 (5): 1329-76.

Manski, C., and S. Lerman. 1977. "The Estimation of Choice Probabilities from Choice Based Samples.” Econometrica 45 (8): 1977-88.

Mas, Alexandre, and Amanda Pallais. 2017. "Valuing Alternative Work Arrangements." A.E.R. 107 (12): 3722-59.

Navarro, S., and J. Zhou. 2016. "Quantifying Credit Constraints, Preferences, and Uncertainty in a Lifecycle Model of Schooling Choice." Working paper, Dept. Econ., Univ. Western Ontario.

Papke, Leslie, and Jeffrey Wooldridge. 1996. "Econometric Methods for Fractional Response Variables with an Application to 401(k) Plan Participation Rates." J. Appl. Econometrics 11 (6): 619-32.

Parker, Jonathan A., and Nicholas S. Souleles. Forthcoming. "Reported Effects vs. Revealed-Preference Estimates: Evidence from the Propensity to Spend Tax Rebates." A.E.R.: Insights. 
Rashid, A. 2000. Taliban: Militant Islam, Oil and Fundamentalism in Central Asia. New Haven, CT: Yale Univ. Press.

Savage, L. 1954. The Foundations of Statistics. New York: Wiley.

Singer, P. 2001. "Pakistan's Madrassahs: Ensuring a System of Education not Jihad." Brookings Inst. Analysis Paper no. 41, Washington, DC.

Solis, A. 2017. "Credit Access and College Enrollment." J.P.E. 125 (2): 562-622.

Steel, R. P., and N. K. Ovalle. 1984. "A Review and Meta-Analysis of Research on the Relationship between Behavioral Intentions and Employee Turnover." J. Appl. Psychology 69:673-86.

Stinebrickner, R., and T. Stinebrickner. 2008. "The Effect of Credit Constraints on the College Drop-Out Decision: A Direct Approach Using a New Panel Study." A.E.R. 98 (5): 2163-84.

_ 2014a. "Academic Performance and College Dropout: Using Longitudinal Expectations Data to Estimate a Learning Model.” J. Labor Econ. 32 (3): $601-44$.

. 2014b. "A Major in Science? Initial Beliefs and Final Outcomes for College Major and Dropout." Rev. Econ. Studies 81 (1): 426-72.

Task Force on Higher Education and Society. 2000. "Higher Education in Developing Countries: Peril and Promise." World Bank Report. Available at http:// www.tfhe.net/report/readreport.htm.

Todd, P., and K. Wolpin. 2006. "Assessing the Impact of a School Subsidy Program in Mexico: Using a Social Experiment to Validate a Dynamic Behavioral Model of Child Schooling and Fertility." A.E.R. 96 (5): 1384-1417.

Train, K. 2009. Discrete Choice Methods with Simulation. Cambridge: Cambridge Univ. Press.

Willis, R., and S. Rosen. 1979. "Education and Self-Selection." J.P.E. 87 (5): S7S36.

Wiswall, M., and B. Zafar. 2015. "Determinants of College Major Choice: Identification Using an Information Experiment." Rev. Econ. Studies 82 (2): 791-824.

- 2018. "Preference for the Workplace, Investment in Human Capital, and Gender." Q.J.E. 133 (1): 457-507.

Zafar, B. 2011a. "Can Subjective Expectations Data Be Used in Choice Models? Evidence on Cognitive Biases." J. Appl. Econ. 26 (3): 520-44.

. 2011b. "How Do College Students Form Expectations?" J. Labor Econ. 29 (2): 301-48.

. 2013. "College Major Choice and the Gender Gap." J. Human Resources 48 (3): 545-95. 